ARTICLE

DOI: $10.1038 / s 41467-018-06307-w$

\title{
Mechanotransduction is required for establishing and maintaining mature inner hair cells and regulating efferent innervation
}

\author{
Laura F. Corns ${ }^{1}$, Stuart L. Johnson ${ }^{1}$, Terri Roberts ${ }^{2}$, Kishani M. Ranatunga ${ }^{2}$, Aenea Hendry ${ }^{1}$, Federico Ceriani id ${ }^{1}$, \\ Saaid Safieddine ${ }^{3}$, Karen P. Steel ${ }^{4}$, Andy Forge (10 ${ }^{5}$, Christine Petit ${ }^{3,6}$, David N. Furness ${ }^{7}$, Corné J. Kros ${ }^{2}$ \& \\ Walter Marcotti id ${ }^{1}$
}

In the adult auditory organ, mechanoelectrical transducer (MET) channels are essential for transducing acoustic stimuli into electrical signals. In the absence of incoming sound, a fraction of the MET channels on top of the sensory hair cells are open, resulting in a sustained depolarizing current. By genetically manipulating the in vivo expression of molecular components of the MET apparatus, we show that during pre-hearing stages the MET current is essential for establishing the electrophysiological properties of mature inner hair cells (IHCs). If the MET current is abolished in adult IHCs, they revert into cells showing electrical and morphological features characteristic of pre-hearing IHCs, including the re-establishment of cholinergic efferent innervation. The MET current is thus critical for the maintenance of the functional properties of adult IHCs, implying a degree of plasticity in the mature auditory system in response to the absence of normal transduction of acoustic signals.

\footnotetext{
${ }^{1}$ Department of Biomedical Science, University of Sheffield, Sheffield S10 2TN, UK. ${ }^{2}$ School of Life Sciences, University of Sussex, Falmer, Brighton BN1 9QG, UK. ${ }^{3}$ Unité de Génétique et Physiologie de I'Audition, Institut Pasteur, 75015 Paris, France. ${ }^{4}$ Wolfson Centre for Age-Related Diseases, King's College London, London SE1 1UL, UK. ${ }^{5}$ UCL Ear Institute, University College London, London SE1 1UL, UK. ${ }^{6}$ Collège de France, 75005 Paris, France. ${ }^{7}$ School of Life Sciences, Keele University, Keele ST5 5BG, UK. Correspondence and requests for materials should be addressed to W.M. (email: w.marcotti@sheffield.ac.uk)
} 
T he sense of hearing relies on sound evoking the displacement of stereociliary bundles projecting from the upper surface of hair cells. Hair bundle displacement causes the opening of mechanoelectrical transducer (MET) channels located at the tips of the shorter and middle rows of stereocilia, and the transduction of acoustic information into a receptor potential inside the hair cells. Stereocilia are interconnected by several extracellular linkages ${ }^{1}$, including tip links that are directly involved in gating the MET channels. While tip links are formed by cadherin $23(\mathrm{CDH} 23)$ and protocadherin $15(\mathrm{PCDH} 15)^{2}$, several other proteins are involved in tensioning and anchoring these links ${ }^{3}$. In the absence of sound, a fraction of the MET channels are normally open, allowing a standing depolarizing current into the hair cells that is mainly carried by $\mathrm{K}^{+}$and $\mathrm{Ca}^{2+}$. Calcium entry through the MET channels causes adaptation and reduces their open probability ${ }^{4}$. However, the endolymph that surrounds the hair bundle has a low $\mathrm{Ca}^{2+}$ concentration in both pre-hearing (second post-natal week: $\sim 300 \mu \mathrm{M})^{5}$ and adult $(\sim 20-40 \mu \mathrm{M})^{6}$ cochleae, resulting in a larger in vivo resting open probability of the MET channel. The driving force for the MET current is provided by an electrical gradient between the endocochlear potential (pre-hearing: $\sim+20 \mathrm{mV}$; adult: $\sim+90 \mathrm{mV})^{7}$ and the hair-cell resting potential $(\sim-60 \mathrm{mV})^{8}$. Although the resting MET current contributes to setting the membrane potential of pre-hearing and adult inner hair cells (IHCs) $)^{5,8}$, its functional implication for IHC development is currently unknown.

Before the onset of hearing, IHCs fire spontaneous $\mathrm{Ca}^{2+}$ action potentials (APs) $)^{9,10}$, which play a crucial role in promoting neuronal survival ${ }^{11}$ and the refinement of the immature auditory system $^{12,13}$. Functionally mature IHCs respond to sound stimulation with graded receptor potentials. This change in the receptor potential requires a completely new complement of basolateral ion channels that appear just before the onset of hearing ${ }^{9,14}$. We hypothesize that, in the immature cochlea, the functional MET channels together with the maturing endocochlear potential ${ }^{7}$ and endolymphatic $\mathrm{Ca}^{2+}$ concentration ${ }^{5}$, trigger the developmental switch from spiking IHCs to high-frequency signal transducers.

Using transgenic mice to manipulate the expression of molecular components of the MET apparatus in vivo, we demonstrate that the MET current is required for their developmental switch from immature to functional sensory receptors. Moreover, we found that the resting MET current in adult IHCs is required for maintaining their mature biophysical identity. The loss of the MET current in adult IHCs causes them to revert to an immature, pre-hearing phenotype and they re-acquire efferent innervation.

\section{Results}

MET channel failure prevents the maturation of IHCs. Protocadherin 15 (PCDH15) is localized to the lower part of the tip link where it contacts the top of the shorter rows of stereocilia. Mutations in Pcdh15 lead to hair-bundle disruption and loss of the MET current from early postnatal days ${ }^{15}$. Therefore, we investigated whether the absence of the MET current in PCDH15 deficient mice affected hair cell maturation. IHCs acquire most of their mature biophysical and morphological characteristics around the onset of hearing $(\sim \mathrm{P} 12)$. This includes the expression of a rapidly activating large conductance $\mathrm{Ca}^{2+}$-activated $\mathrm{K}^{+}$ current $\left(I_{\mathrm{K}, \mathrm{f}}\right)^{9}$ and a $\mathrm{K}^{+}$current $\left(I_{\mathrm{K}, \mathrm{n}}\right)^{14}$ carried by KCNQ4 channels. We found that $I_{\mathrm{K}, \mathrm{f}}$ was present in adult control IHCs (Pcdh15+/av3J: Fig. 1a, $3.8 \pm 0.5 \mathrm{nA}$ at $-25 \mathrm{mV}, n=10$, mean \pm SEM; see Methods for details) but absent in Pcdh15av3/av3J mutant mice (Fig. 1b). The absence of $I_{\mathrm{K}, \mathrm{f}}$ in Pcdh15 av3J/av3J unmasked the inward $\mathrm{Ca}^{2+}$ current $(-252 \pm 23 \mathrm{pA}, n=12)$. The size of $I_{\mathrm{K}, \mathrm{n}}$ was significantly reduced in $P c d h 15^{\text {av3J/av3J }}$ IHCs $(-68 \pm 11 \mathrm{pA}$ at $-124 \mathrm{mV}, n=8, P<0.0001, t$-test; see
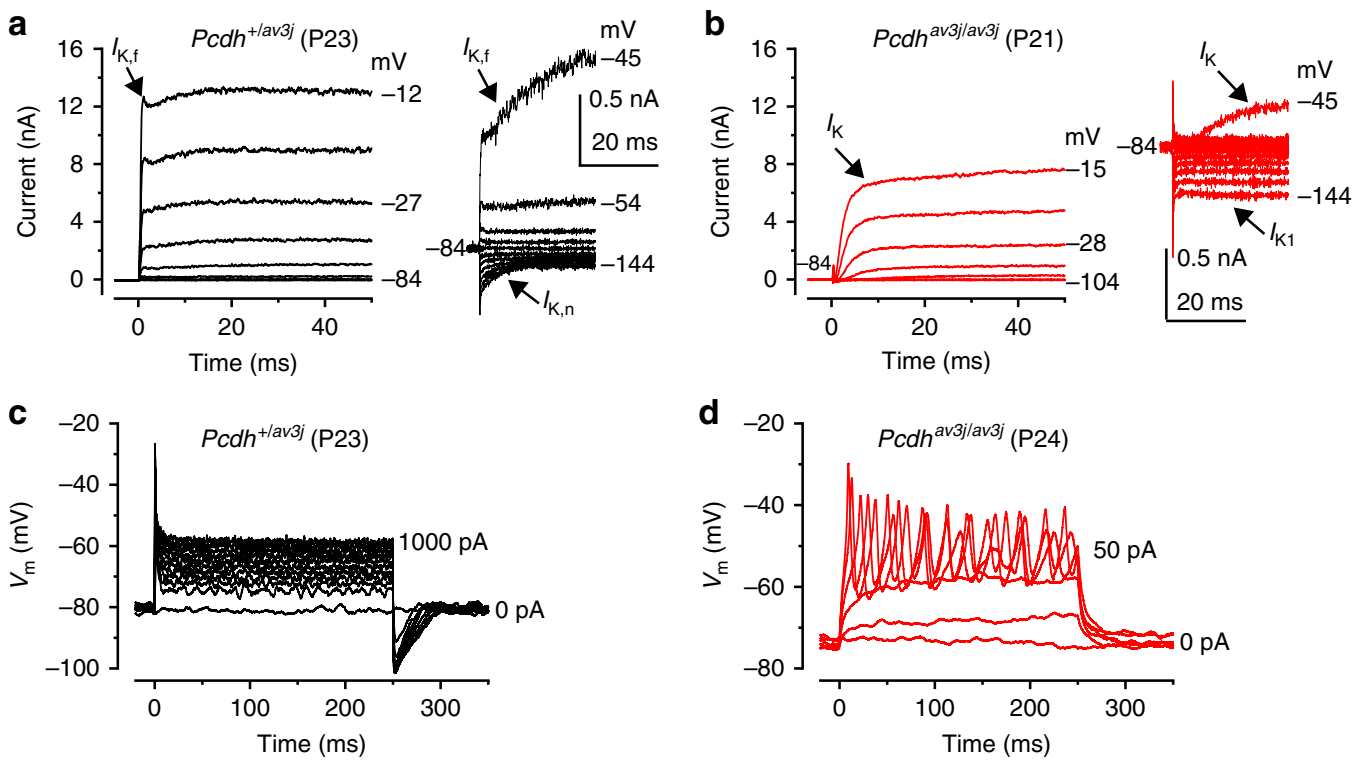

Fig. 1 Current and voltage responses from IHCs of Pcdh15 mutant mice. a, b Potassium currents recorded from IHCs of control Pcdh15 ${ }^{+/ a v 3 j}$ (a) and

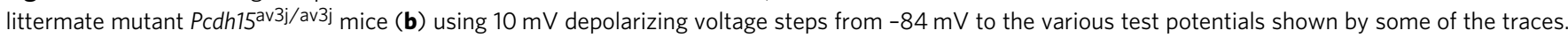
The adult-type currents $\left(I_{K, f}\right.$ and $\left.I_{K, n}\right)$ were only present in IHCs from control Pcdh15 ${ }^{+/ a v 3 j}$ mice (a). IHCs from Pcdh15av3j/av3j mice retained the currents characteristic of immature cells ( $\mathbf{b}, I_{\mathrm{K}}$ and $I_{\mathrm{K} 1}$ ). The absence of the rapidly activating $I_{\mathrm{K}, \mathrm{f}}$ in $P$ cdh 15 av3j/av3j IHCs is also evident when comparing the activation time course of the total outward currents on an expanded time scale (see insets). $\mathbf{a}, \mathbf{b}$ are representative recordings from 10 ( 3 mice) and 12 (3 mice) IHCs, respectively. c, d Voltage responses elicited by applying depolarizing current injections to control, Pcdh15 $5^{+/ a v 3 j} \mathbf{c}$ and mutant, Pcdh15av3j/av3j d IHCs from their resting membrane potentials. Depolarizing current injections caused slow APs in the Pcdh15avj3/av3j mutant IHC. c, d are representative recordings from 8 ( 3 mice) and 15 (3 mice) IHCs, respectively. Recordings were performed near body temperature 
Methods for details) compared to that of $P c d h 15^{+/ a v 3 J}$ control cells $(-216 \pm 17 \mathrm{pA}, n=8)$. Pcdh15 $5^{\text {av3J/av3J }}$ IHCs retained an immature phenotype by expressing the inward $\left(I_{\mathrm{K} 1}\right)$ and slowlyactivating outward $\left(I_{\mathrm{K}}\right) \mathrm{K}^{+}$currents $^{14,16}$. The size of $I_{\mathrm{K}}$, calculated as the difference between the steady-state and early $\left(I_{\mathrm{K}, \mathrm{f}}\right)$ current was $2.4 \pm 0.5 \mathrm{nA}\left(P c d h 15^{+/ a v 3 J}\right)$ and $1.6 \pm 0.2 \mathrm{nA}\left(P c d h 15^{\text {av3J/av3J }}\right)$ $(P=0.159, t$-test $)$. The physiological consequence of the imma-

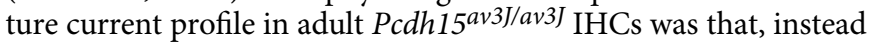
of generating rapid and graded voltage responses characteristic of adult IHCs (Fig. 1c), they retained the ability to fire action potentials (APs) (Fig. 1d), a characteristic of pre-hearing IHCs ${ }^{14}$. A similar failure in the acquisition of the mature current profile has also been reported in IHCs from mice lacking other stereociliary bundle proteins, including the transmembrane channellike protein 1 (TMC1) (Deafness mouse) ${ }^{17}$, which is necessary for mechanoelectrical transduction ${ }^{18}$, and the unconventional Myo6 (Snell's waltzer mouse) ${ }^{19}$, which is required for the development of the MET apparatus ${ }^{20}$. The above findings indicate the existence of a link between a functional MET apparatus and IHC maturation. Mutations in or absence of stereociliary proteins early in development normally causes severe morphological defects of the stereociliary bundle (e.g. Myo6; ${ }^{21}$ Myo7a; ${ }^{22}$ harmonin $\left.^{23}\right)$. We used targeted knockouts obtained by crossing floxed mice (Ush1 $c^{f l f l}$ and Myo7afl/fl) with Myo15-cre crl- mice $^{24}$. Because the temporal expression of the cre driven by the hair cell specific Myo15 promoter occurs postnatally ( P 4 in the cochlear apical coil $)^{24}$, the stereociliary bundle develops normally, allowing us to study the functional implications of the missing protein.

The MET current drives IHC maturation. Harmonin is a scaffolding protein that contributes to the attachment of the upper end of the tip link to the actin filament of the stereocilia ${ }^{25}$. In Ush1c (harmonin) mutant mice the MET channel lacks the resting current and by P7 the MET current is almost completely absent ${ }^{23}$. Although the harmonin-a isoform has been implicated in $\mathrm{Ca}^{2+}$ channel regulation, this role is restricted to post-hearing $\mathrm{IHCs}^{26}$. Therefore, we recorded MET currents from Ush $1 c^{f l f l}$ and Ush $1 d^{f l / f l}$ Myo15-cre ${ }^{+/-}$immature IHCs (Fig. 2) by displacing the hair bundles ${ }^{4}$. At P7 the size of the maximum MET current was similar between the two genotypes (Ush1c fl/fl: $-1117 \pm 83 \mathrm{pA}$, $n=4 ;$ Ush $1 c^{f l f l}$ Myo15-cre ${ }^{+l-}:-1043 \pm 311 \mathrm{pA}, n=2$, measured at $-121 \mathrm{mV}, P=0.763, t$-test, Fig. $2 \mathrm{a}, \mathrm{b})$. The absence of a clear phenotype at the end of the first postnatal week agrees with previous observations using the Myo15-cre mouse to knockdown another stereociliary protein (sans) ${ }^{24}$. However, at P8 (Fig. 2b) the size of the MET current was already significantly smaller in $U$ sh $1 c^{f l f l} M y o 15-$ cre $^{+l-}(-828 \pm 77 \mathrm{pA}, n=3, P<0.04, t$-test $)$ compared to control cells (Ush1cflf: $-1079 \pm 61 \mathrm{pA}, n=6$ ), and it deteriorated rapidly thereafter such that by P10 it was almost absent in Ush1c $c^{f l f l} M y o 15-\mathrm{cre}^{+/-}$IHCs (Fig. 2c, d; Ush $1 c^{f l / f l}$ $-676 \pm 41 \mathrm{pA}, n=9 ;$ ssh $^{\mathrm{fl}} \mathrm{f}^{\prime} \mathrm{fl}_{\mathrm{Myo}} 15-\mathrm{cre}^{+/-}-73 \pm 30 \mathrm{pA}, n=17$, P10-P12, $P<0.0001, t$-test). The fraction of the MET channel open at rest in P10-P12 IHCs was negligible in Ush $1 c^{f l / f l} M y o 15-$ cre $^{+/-}$mice (at $-121 \mathrm{mV}: 0.003 \pm 0.001$; at $+99 \mathrm{mV}: 0.010 \pm$ $0.007, n=17)$ and significantly reduced compared to that of control cells (Ush1ctlfl at $-121 \mathrm{mV}: 0.036 \pm 0.008$, at $+99 \mathrm{mV}$ : $0.120 \pm 0.034, n=6, P<0.0001, t$-test). Despite the abnormal MET current, the hair bundles of Ush $1 c^{\text {fl/fl }} M$ yo $15-$ cre $^{+/-}$IHCs acquired the characteristic staircase structure and appeared qualitatively similar to littermate controls at P15 (Fig. 2e). Using TEM, we quantified the height and width of the tallest (s1) and second tallest (s2) stereocilia in P25 IHCs. Although the height and width of s1 were not significantly different between the two genotypes $(P<0.7068$ and $P<0.3788$, $t$-test, respectively, Fig. $2 \mathrm{f})$, the former showed greater variability in $U s h 1 c^{f l f l} M y o 15-\mathrm{cre}^{+/-}$ IHCs. The height and width of s2 for Ush $1 c^{f l / f l} M y o 15-\mathrm{cre}^{+/-}$IHCs $(1.42 \pm 0.14 \mu \mathrm{m}$ and $0.35 \pm 0.07 \mu \mathrm{m}$, respectively, mean $\pm \mathrm{SD}, n=$ 7 IHCs) were significantly reduced compared to control cells $(1.78 \pm 0.14 \mu \mathrm{m}, \quad P<0.0005 ; 0.45 \pm 0.03 \mu \mathrm{m}, \quad P<0.0066, t$-test, respectively, $n=7$ IHCs, Fig. $2 \mathrm{f})$. The reduced s 2 compared to $\mathrm{s} 1$ in $U s h 1 c^{f l f l} M y o 15-c^{+/-}$IHCs, meant that the s1/s2 ratio was increased (3.16 \pm 0.57$)$ compared to control cells $(2.37 \pm 0.12, P<$ $0.0036, t$-test). Finally, s2 in IHCs from Ush1ctlfl Myo15-cre ${ }^{+/-}$ mice tended to show rounded tips rather than the characteristic prolate-shaped stereocilia tips of controls (Fig. 2f), which strongly suggests that the tip links are absent. Although some prolateshaped stereocilia tips were present is s2 at P15 in Ush $1 c^{f l}$ ${ }^{f}$ Myo15-cre ${ }^{+/-}$mice, they were less evident than those in controls (Supplementary Fig. 1), indicating that the loss of the MET current in the absence of Ush1c could be due to the progressive loss of tip links.

A determining factor for the presence of spontaneous AP activity in pre-hearing IHCs (second post-natal week) is the resting membrane potential $\left(V_{\mathrm{m}}\right)$, which has to be close to the activation threshold of the $\mathrm{Ca}^{2+}$ current. In IHCs $V_{\mathrm{m}}$ is determined by the balance between an inward, depolarizing resting MET current and outward $I_{\mathrm{K}}{ }^{5}$. Therefore, we investigated whether the substantially reduced resting MET current in immature IHCs from $U s h 1 c^{f l / f l} M y o 15-\mathrm{cre}^{+/-}$mice affected IHC physiology. Since the fraction of MET channels open at rest is determined by $\mathrm{Ca}^{2+}$-dependent adaptation ${ }^{4,27}$, the $V_{\mathrm{m}}$ of IHCs in vitro strongly depends upon the extracellular $\mathrm{Ca}^{2+}$ concentration. Using current clamp, we measured the depolarizing current required to elicit APs in $\mathrm{IHCs}$ at $35-37^{\circ} \mathrm{C}$ using $1.3 \mathrm{mM} \mathrm{Ca}{ }^{2+}$, which is the $\mathrm{Ca}^{2+}$ concentration present in the perilymphatic solution bathing the IHC basolateral membrane. Starting from

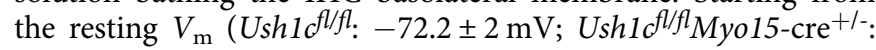
$-74.9 \pm 2 \mathrm{mV}, P=0.257, t$-test), a similar amount of current was required to trigger APs in both control $U s h 1 c^{f l / f l}(75 \pm 7 \mathrm{pA}$, $n=10, \mathrm{P} 9-\mathrm{P} 10)$ and $U s h 1 c^{f l / f l} \mathrm{Myo} 15-\mathrm{cre}^{+l-}(72 \pm 9 \mathrm{pA}, n=13$, P9-P11, $P=0.770$, $t$-test) mice (Fig. $2 \mathrm{~g}$ ). We then measured the resting MET current near the $V_{\mathrm{m}}$ of IHCs in $1.3 \mathrm{mM} \mathrm{Ca}^{2+}$ and at room temperature, and found that it was much smaller (Fig. 2h) than that required to elicit APs (Fig. 2g), even when correcting for body temperature (Fig. 2h). However, the degree of adaptation of the MET channel in vivo should be much reduced as the estimated endolymphatic $\mathrm{Ca}^{2+}$ concentration during the second postnatal week is $0.3 \mathrm{mM}^{5}$. The application of $0.3 \mathrm{mM} \mathrm{Ca} \mathrm{Ca}^{2+}$ increased the resting MET current in control Ush $1 \mathrm{c}^{\mathrm{fl} / \mathrm{fl}} \mathrm{IHCs}$ (Fig. $2 \mathrm{i}, \mathrm{j}$ ) to a value that would depolarize them to their AP firing threshold (Fig. 2g: also see ref. ${ }^{5}$ ), and even more so when values were adjusted for the temperature difference (Fig. 2i). This would also be the case if we were to subtract the resting MET current measured in $1.3 \mathrm{mM} \mathrm{Ca}^{2+}$ (Fig. $2 \mathrm{~h}$ ), which is likely to contribute to the resting $V_{\mathrm{m}}$ and thus to the current required for eliciting repetitive firing (Fig. $2 \mathrm{~g}$ ). The reduced resting MET current in Ush1 $d^{f l f l} \mathrm{Myo} 15-\mathrm{cre}^{+/-}$IHCs bathed in $0.3 \mathrm{mM}$ $\mathrm{Ca}^{2+}$ (Fig. 2i) would not be sufficient to depolarize them to AP threshold. IHCs however would still be able to fire APs in response to ATP-induced $\mathrm{Ca}^{2+}$ waves from surrounding nonsensory cells ${ }^{10,28}$.

We then investigated whether the absence of harmonin from pre-hearing Ush1ollfl Myo15-cre ${ }^{+/-}$IHCs would also affect their basolateral membrane properties. At P7, P9, and P10, the latter being a time when the MET current in mutant IHCs is almost absent (Fig. 2c, d), the biophysical properties of IHCs, including the size of $\mathrm{K}^{+}$currents, resting membrane potential and cell membrane capacitance, were not significantly different between $U \operatorname{sh} 1 e^{f l / f l}$ and $U s h 1 e^{f l / f l} M y o 15-c^{+/-}$mice (Supplementary Table 1, Supplementary Fig. 2). The above data show that the loss of 
a

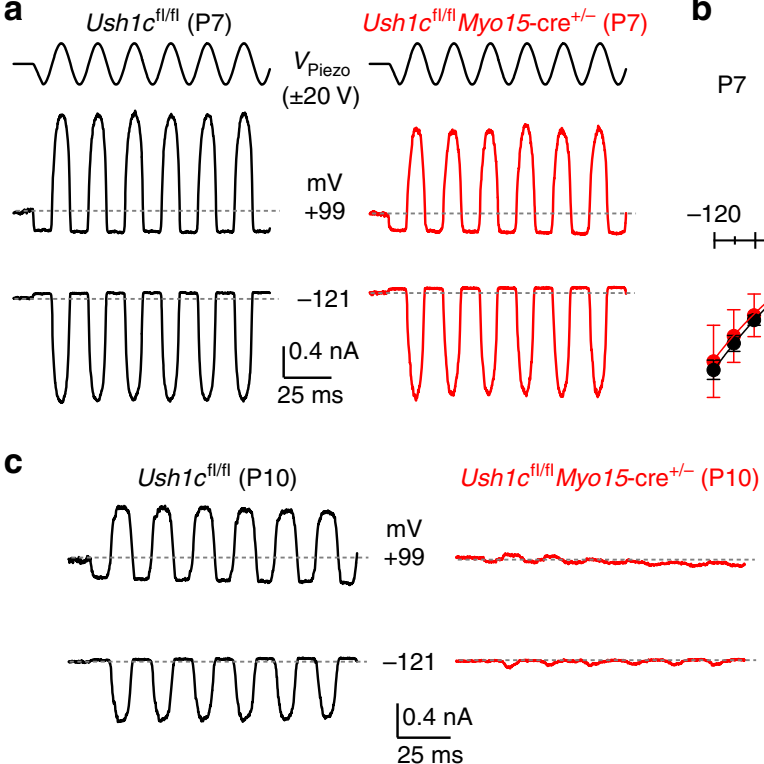

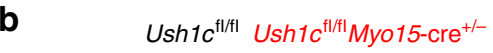
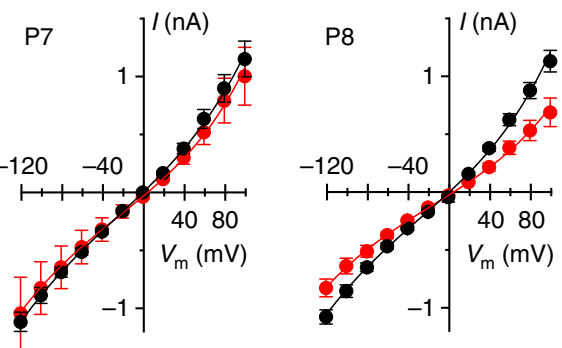

d

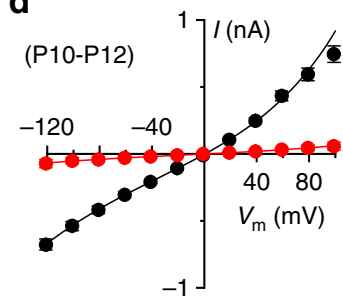

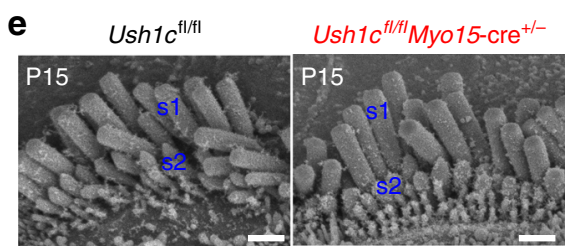

$\mathbf{f}$

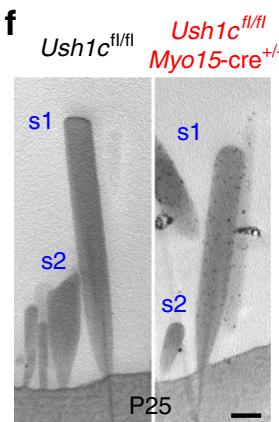

g
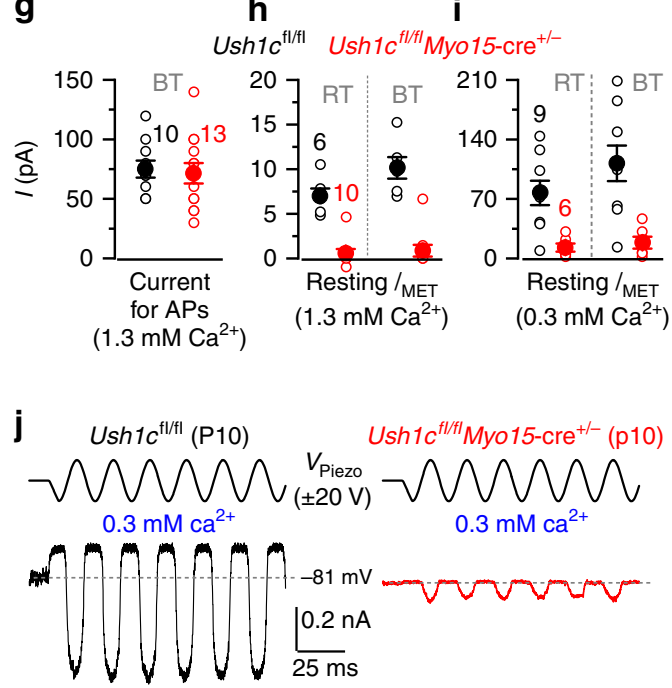

Fig. 2 Disappearance of the MET current in IHCs of Ush $1 c^{f l / f l}$ conditional KO mice. a MET currents recorded in P7 IHCs from control Ush $1 c^{f l / f l}$ and knockout Ush $1 \mathrm{C}^{f / f l}$ Myo15-cre ${ }^{+/-}$mice by displacing the hair bundles while applying $20 \mathrm{mV}$ voltage steps between $-121 \mathrm{mV}$ to $+99 \mathrm{mV}$. For clarity, only the traces at $-121 \mathrm{mV}$ and $+99 \mathrm{mV}$ are shown (dashed lines: holding current; $V_{\text {Piezo }}$ : driver voltage to the fluid jet). b Maximum MET current-voltage curves obtained from P7 (left) and P8 (right) Ush $1 c^{f l / f l}$ and Ush1 $c^{f l / f l} M y 015-$ cre $^{+/-}$IHCs (3 and 6 mice, respectively). c MET currents in P10 IHCs from both genotypes. Protocol as in a. d Maximum MET currents obtained from 9 Ush $1 c^{f l / f l}$ and 17 Ush $1 c^{f l / f l}$ Myo15-cre ${ }^{+/-}$(P10-P12) IHCs (4 and 8 mice, respectively). e SEM images of P15 IHC bundle from both genotypes. Scale bars, $1 \mu \mathrm{m}$. f TEM images (left) of P25 IHC stereocilia from both genotypes. Scale bars, $400 \mathrm{~nm}$. Right panels show the height and width of the tallest (s1) and second tallest (s2) stereocilia in P25 IHCs from Ush $1 c^{f l / f l}$ and Ush $1 c^{f l / f l}$ Myo15-cre ${ }^{+/-}$mice. g Depolarizing current used to elicit repetitive APs in Ush1 $C^{f l / f l}$ (P9-P10, 8 mice) and Ush1 $c^{f l / f l}$ Myo15-cre ${ }^{+/-}$(P9-P11, 7 mice) IHCs. Experimental conditions:

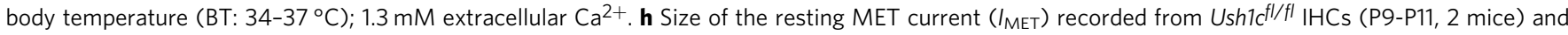
Ush1c ${ }^{I / / f I}$ Myo15-cre ${ }^{+/-}$(P10-P11, 5 mice) IHCs. Room temperature (RT: $22-24^{\circ} \mathrm{C}$, left bars); $1.3 \mathrm{mM}$ extracellular Ca ${ }^{2+}$. I $\mathrm{MET}_{\text {was }}$ interpolated from its current-voltage relation near the $V_{\mathrm{m}}$ of IHCs $\left(-73 \mathrm{mV}\right.$ ). Right bars show the RT values corrected for BT using a $\mathrm{Q}_{10}$ of 1.45 (ref. ${ }^{8}$ ). i Size of the resting $I_{\mathrm{MET}}$

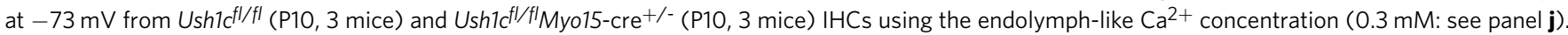
Left and right bars are as described in $\mathbf{h}$. $\mathbf{j} I_{\text {MET }}$ recorded at $-81 \mathrm{mV}$ at P10 from Ush1c fl/fl and Ush $1 c^{f l / f l} M y o 15-\mathrm{cre}^{+/-} \mid \mathrm{HCs}$ in $0.3 \mathrm{mM} \mathrm{Ca}{ }^{2+}$. Protocol as in a. Number of IHCs in $\mathbf{g}$-i is shown above the columns. Average data is shown as mean \pm SEM in $\mathbf{b}, \mathbf{d}, \mathbf{g}$, $\mathbf{h}$ or mean $\pm \mathrm{SD}$ in $\mathbf{f}$

harmonin leads to a gradual disappearance of the MET current without affecting normal development of the basolateral membrane properties of pre-hearing IHCs, including the $\mathrm{Ca}^{2+}$ channels ${ }^{26}$. After the onset of hearing, while young adult (P14-P15) and adult (P29) IHCs from control Ush1c $c^{\text {llfl }}$ mice express both $I_{\mathrm{K}, \mathrm{f}}$ and $I_{\mathrm{K}, \mathrm{n}}$ (Fig. 3a) and exhibit graded voltage responses (Fig. 3c), agematched Ush1c $c^{f l f l}$ Myo15-cre ${ }^{+/-}$IHCs retained an immature current profile (Fig. 3b, Supplementary Table 2 ) and the ability to generate
APs (Fig. 3d). Auditory brainstem responses (ABRs) showed that Ush $1 c^{f l f l}$ Myo15-cre ${ }^{+/-}$mice had severe hearing impairment at P16 (Fig. 3e) and were profoundly deaf at P37-45 (Fig. 3f). Adult mice also exhibit the classical head bobbing and hyperactive circling behavior characteristic of Ush1c mutant mice ${ }^{29}$. The above results indicate that the acquisition of the mature basolateral membrane profile in IHCs requires a functional MET current during prehearing stages of development. 

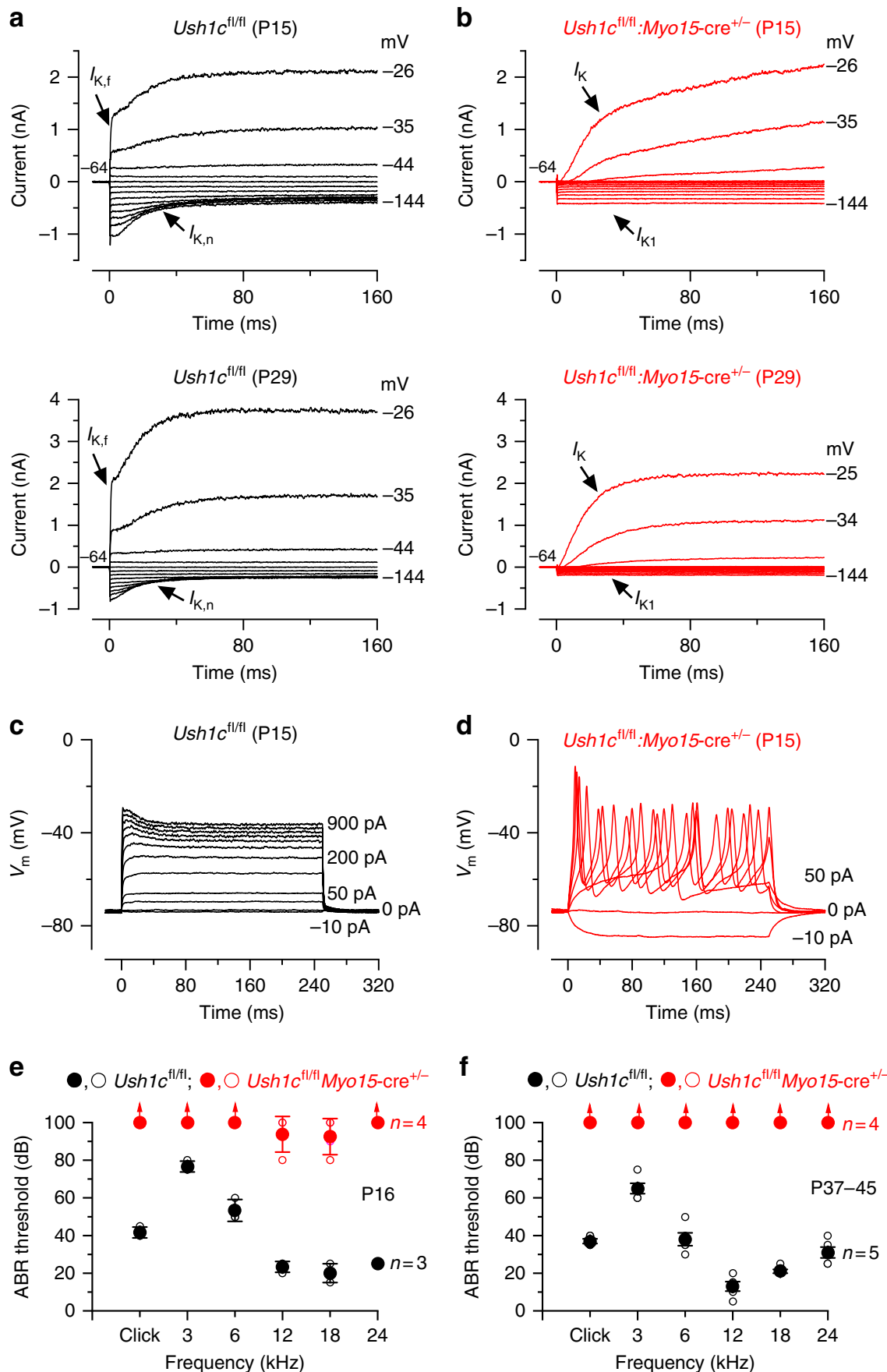

Fig. $3 \mathrm{IHCs}$ from Ush1 $\mathrm{c}^{f / / f l}$ Myo15-cre ${ }^{+/-}$conditional knockout mice fail to mature. a, b Potassium currents recorded from P15 (upper panels) and P29 (lower

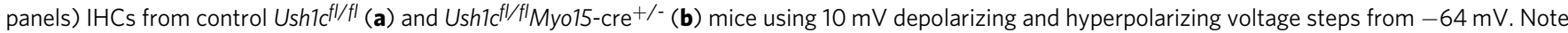
that the $\mathrm{K}^{+}$currents characteristic of adult IHCs $\left(I_{K, f}\right.$ and $\left.I_{K, n}\right)$ were only present in IHCs from control Ush $1 c^{f l / f l}$ mice (a). IHCs from Ush $1 c^{f l / f l}$ Myo15-cre ${ }^{+/-}$ mice retained the $\mathrm{K}^{+}$currents characteristic of pre-hearing stages $\left(I_{\mathrm{K}}\right.$ and $\left.I_{\mathrm{K} 1}\right)$. c, $\mathbf{d}$ Voltage responses elicited by applying hyperpolarizing and depolarizing current injections from the respective membrane potentials in P15 IHCs of control Ush $c^{f l / f l}$ (c) and Ush $1 c^{f l / f l}$ Myo15-cre ${ }^{+/-}$(d) mice. Note that APs are still present in post-hearing Ush1 $c^{f / / f l}$ Myo15-cre ${ }^{+/-} \mid \mathrm{HCs}$. For more details see Supplementary Table 2. e, f Mean ABR thresholds ( \pm SD ) for clicks and pure tone stimulation from $3 \mathrm{kHz}$ to $24 \mathrm{kHz}$ obtained from control Ush1 $\mathrm{fl}^{f / f l}$ and littermate Ush1c ${ }^{f / / f l}$ Myo15-cre ${ }^{+/-}$mice at P16 (e) and P37-45 (f). Ush1c $c^{f l / f l}$ Myo15-cre $+/-$ mice are almost completely deaf already at P16. Open symbols represent data from single mice. Closed symbols represent averages (mean \pm SEM)

Mature IHCs regress without the MET current. The unconventional myosin VIIa (Myo7a) is another hair cell protein that binds to harmonin ${ }^{30}$. In the absence of Myo7a no MET current is present at rest ${ }^{31}$, stereociliary bundles gradually degenerate $\left(\text { Myo7ash }^{\text {shJ } / s h 6 J} \text { mice }\right)^{31}$ and the $\mathrm{K}^{+}$current profile of adult IHCs retains pre-hearing characteristics (Supplementary Fig. 3). Different from pre-hearing $U s h 1 c^{f l f l} M y o 15-\mathrm{cre}^{+/-}$mice (Fig. 2), the size $(-648 \pm 40 \mathrm{pA}$ at $-121 \mathrm{mV}, n=6,3$ mice, P9-P10) and resting open probability $(0.026 \pm 0.004 \mathrm{pA}, n=6)$ of the MET current in IHCs of pre-hearing Myo7afl/fl Myo15-cre ${ }^{+/-}$mice was similar to that measured in control Myo7aflfl $\mathrm{IHCs}(-725 \pm 38$ $\mathrm{pA}, P=0.225$, $t$-test; $0.038 \pm 0.010 \mathrm{pA}, P=0.2318, t$-test, $n=4,3$ mice, P10) (Fig. 4a, b). The normal MET current in pre-hearing Myo7 $a^{f l / f l} M y o 15-\mathrm{cre}^{+/-}$IHCs (Fig. 4a, b), but not in 
a

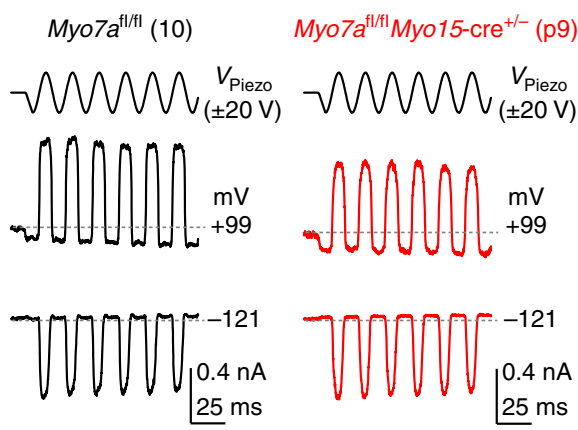

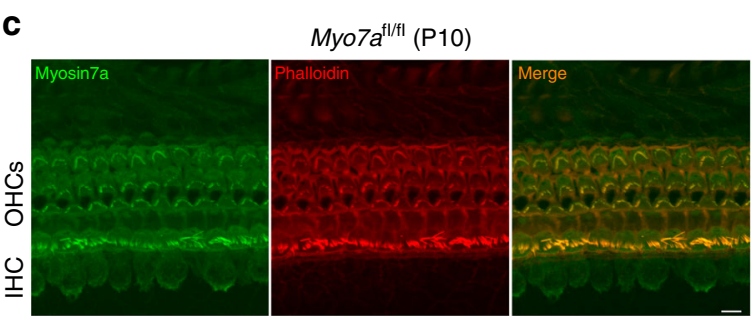

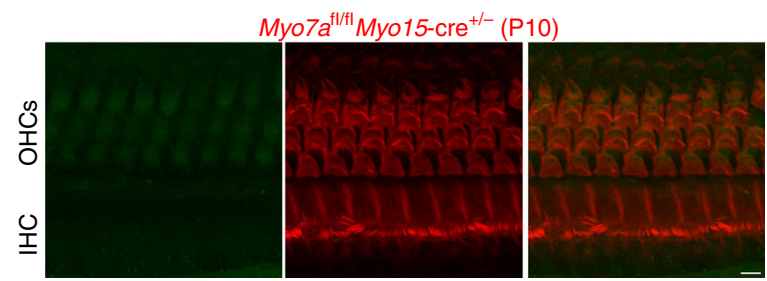

d
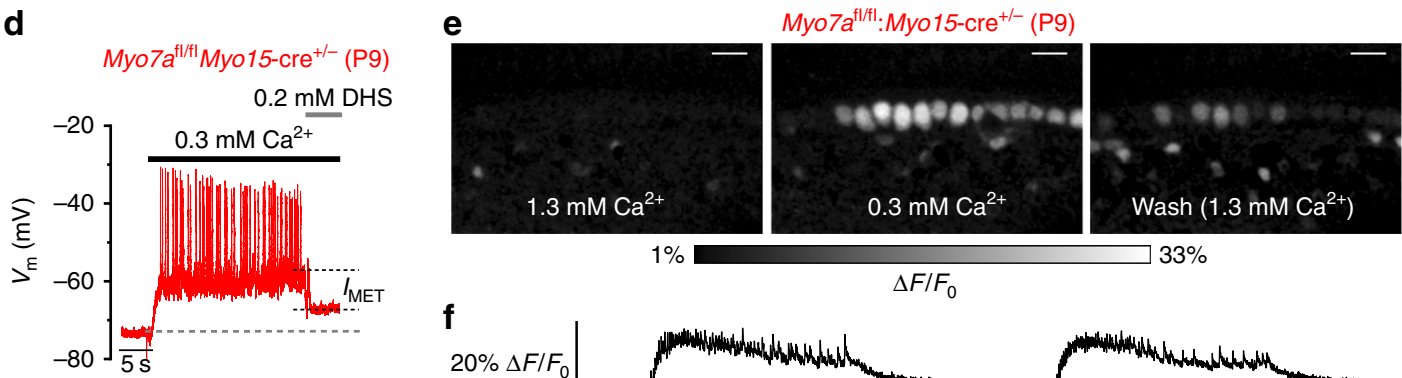

$1 \%$

$\Delta F / F_{0}$
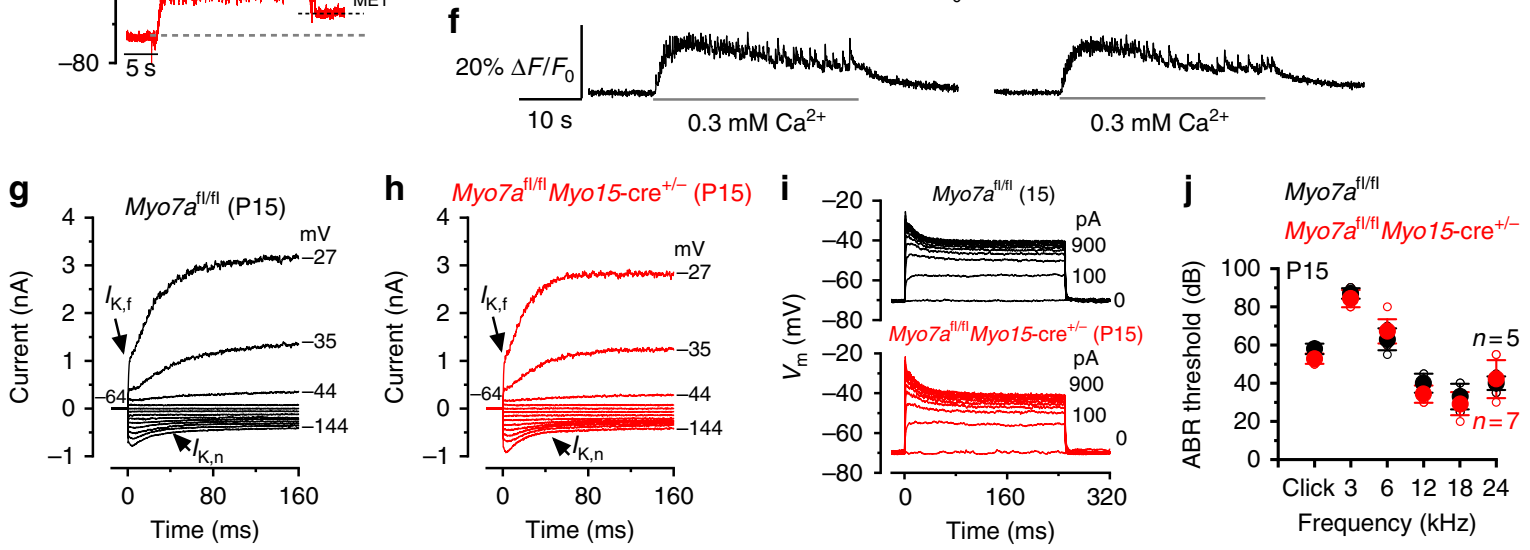

Fig. $4 \mathrm{IHCs}$ from Myo7 $a^{f / / f l} M y 015-\mathrm{cre}^{+/-}$conditional knockout mice acquire their mature phenotype. a, b MET currents from IHCs of control Myo7a $a^{f l / f l}$ (left, P10) and knockout Myo7afl/flMyo15-cre ${ }^{+/-}$(right, P9) mice. The experimental protocol is as in Fig. 2. c Cochlear whole mount preparations from P10 Myo7a fl/fl (control, upper panel) and Myo7a ${ }^{f l / f l} M y 015-c^{+/-}$(lower panel) mice, immunostained for Myo7a (green) and for F-actin with phalloidin (red). Myo7a is detected in both OHCs and IHCs in the Myo7a $a^{f / f l}$ mouse, but not in the Myo7 $\mathrm{fl}^{f / f l}$ Myo15-cre ${ }^{+/-}$mouse (but see also Supplementary Fig. 4 for one example of normal hair cell Myo7a labeling in a P10 Myo7a fl/fl Myo15-cre ${ }^{+/-}$mouse). Scale bars, $5 \mu \mathrm{m}$. $\mathbf{d}$ IHC voltage response recorded during the superfusion of $0.3 \mathrm{mM} \mathrm{Ca}^{2+}$ alone and together with the MET channel blocker DHS (0.2 mM) in a Myo7afl/fl Myo15-cre ${ }^{+/-}$mouse. The MET depolarizing current substantially contributes to the IHC membrane potential. e Images showing relative fluo-4 fluorescence changes $\left(\Delta F / F_{0}\right)$ before (left) during (middle) and after (right) application of an extracellular solution containing $0.3 \mathrm{mM} \mathrm{Ca}^{2+}$. Images were obtained as maximal back projection (200 frames, $6.6 \mathrm{~s}$ ). Scale bar, $15 \mu \mathrm{m}$. f Representative $\Delta F / F_{0}$ traces from two IHCs (from images in panel e) during bath application of $0.3 \mathrm{mM} \mathrm{Ca}{ }^{2+}$. Traces are computed as pixel averages of regions of interest centered on IHCs. $\mathrm{Ca}^{2+}$ spikes are evident in $\mathrm{IHC}$; however, the relative long fluorescence decay time constant of the $\mathrm{Ca}^{2+}$ signal, prevents the isolation of single APs during high-frequency bursting. $\mathbf{g}, \mathbf{h}$ Current responses in post-hearing IHCs (P15) from control (g) and Myo7afl/flMyo15-cre ${ }^{+/-}(\mathbf{h})$ mice. Note that both $I_{K, f}$ and $I_{K, n}$ are present in IHCs from both genotypes. Voltage protocol as in Fig. 3a. i Voltage responses recorded from P15 IHCs of control Myo7a $\mathrm{al}^{\mathrm{fl} / \mathrm{fl}}$ (top panel) and Myo7a fl/flMyo15-cre $\mathrm{fl}^{+/-}$(lower panel) P15 IHCs (protocol as in Fig. 3c). Panel ( $\left.\mathbf{g}, \mathbf{j}: M y o 7 a^{f / / f l}\right)$ and (b, j: Myo7a $a^{f / f l} M y o 15-c^{+/-}$) are representative recordings from 9 IHCs (4 mice) and 8 IHCs (4 mice), respectively. j Mean ABR thresholds $( \pm \mathrm{SD}$ ) for clicks and frequency-specific pure tone stimulation from $3 \mathrm{~Hz}$ to $24 \mathrm{kHz}$ obtained from control Myo7afl/fl and littermate Myo7a $a^{f / f l}$ Myo15-cre ${ }^{+/-}$mice at P15

Ush $1 d^{f l / f l}$ Myo15-cre ${ }^{+/-}$cells (Fig. 2), suggests a possible slower turnover of Myo7a, compared to that of harmonin. This is supported by the normal appearance of Myo7a immunostaining in hair cells from one out of four P10 mice tested (Fig. 4c; Supplementary Fig. 4). Alternatively, the late phenotype in Myo7afl/fl Myo15-cre ${ }^{+l-}$ IHCs could reflect a distinct, and as yet undefined, role for Myo7a in mechanoelectrical transduction.
The aforementioned experiments (Fig. 2g-j) show that the resting MET current is required for the generation of spontaneous APs in IHCs during the last days preceding the onset of hearing. The normal MET current in IHCs of Myo7a $f^{f l f l}$ Myo15-cre ${ }^{+/-}$mice meant that superfusion of the estimated endolymphatic $\mathrm{Ca}^{2+}$ concentration $\left(0.3 \mathrm{mM} \mathrm{Ca}^{2+}\right)^{5}$, caused them to depolarize to near the expected in vivo resting $V_{\mathrm{m}}$ and elicited repetitive APs 
(Fig. $4 \mathrm{~d}-\mathrm{f}$ ). The incomplete repolarization of IHC by the MET channel blocker dihydrostreptomycin (DHS) is due to the low $\mathrm{Ca}^{2+}$ solution additionally affecting basolateral membrane SK2 channels through the small hole in the epithelium created to gain access to the cell with the patch pipette ${ }^{5}$. Indeed, two-photon confocal $\mathrm{Ca}^{2+}$ imaging experiments, in which the sensory epithelium is kept intact, showed that $0.3 \mathrm{mM} \mathrm{Ca}{ }^{2+}$ caused IHCs to fire $\mathrm{Ca}^{2+}$ spikes superimposed on a sustained increase in fluorescence (Fig. 4e, f), confirming that the MET current-induced IHC depolarization by endolymphatic $\mathrm{Ca}^{2+}$ is sufficient to generate repetitive APs. The normal development of IHCs in Myo7afl/fl Myo15-cre ${ }^{+/-}$mice meant that post-hearing cells (P14-P15) acquired current and voltage responses similar to control Myo7aflfl cells (Fig. 4g-i; Supplementary Table 3), further supporting the hypothesis that a normal resting MET current, and the associated AP activity, is required for the final IHC functional differentiation. Moreover, at P15, Myo7a $a^{f l f l}$ Myo15-cre ${ }^{+/-}$mice show ABRs comparable to those of control mice (click thresholds: Myo7 allfl $58 \pm 3 \mathrm{~dB}, n=5$; Myo7afl/fl Myo15-cre ${ }^{+/-} 53 \pm 3 n=7$; Fig. 4j). ABR thresholds at all frequencies tested were also similar between the two genotypes (two-way ANOVA, $P=0.174$ ).

Despite normal ABR thresholds in P15 Myo7afl/fl Myo15-cre ${ }^{+/-}$mice, the MET current became progressively affected from P14 compared to control Myo7allft IHCs (Fig. $5 \mathrm{a}-\mathrm{c})$. The size of the MET current and the fractional resting open probability of the channel in control IHCs (Myo7afl/fl: $-974 \pm 63$ pA, $0.108 \pm 0.028, n=6$, respectively, measured at $-121 \mathrm{mV}, \mathrm{P} 15$ ) were significantly larger than those from Myo7atlfl $M y o 15-\mathrm{cre}^{+/-}$ cells at P14 $(-669 \pm 96 \mathrm{pA}, n=4, P<0.05 ; 0.011 \pm 0.014, P<0.05)$ and P16 $(-377 \pm 64 \mathrm{pA}, n=6, P<0.001 ; 0.031 \pm 0.014, P<0.05)$ (one-way ANOVA). The smaller MET current in Myo7afl/fl Myo15-cre ${ }^{+/-}$IHCs after the onset of hearing occurred despite the normal appearance of the stereociliary bundles and the presence of tip links as well as prolate-shaped stereocilia tips (P30: Fig. 5d). Using TEM we found that the height and width of stereocilia in the tallest (s1) and second tallest (s2) rows in P37 IHCs were not significantly different between the two genotypes (Fig. 5e). The gradual loss of MET current was followed by a progressive disappearance of the adult-type $\mathrm{K}^{+}$currents $\left(I_{\mathrm{K}, \mathrm{f}}\right.$ and $\left.I_{\mathrm{K}, \mathrm{n}}\right)$, such that by P59 Myo7aflfl Myo15-cre ${ }^{+/-}$IHCs exhibited an immature current profile (Fig. 5f-i; Supplementary Table 3), including a slowly-activating outward $\left(I_{\mathrm{K}}\right)$ and an inward rectifier $\left(I_{\mathrm{K} 1}\right) \mathrm{K}^{+}$current $^{14,16}$. IHCs from control mice $\left(M y o 7 a^{f l f l}\right.$ : Fig. 5f-h; Supplementary Table 3; Myo15-cre $\mathrm{c}^{+/-}$: Supplementary Fig. 5; Supplementary Table 4) had the characteristic current profile of mature wild-type mice ${ }^{9,14}$.The size of IHCs, which is reported as cell membrane capacitance $\left(C_{\mathrm{m}}\right.$ : Fig. $\left.5 \mathrm{i}\right)$, became smaller with age in both Myo7aflfl and Myo7 fllfl Myo15-cre ${ }^{+/-}$ IHCs, although it occurred earlier in the latter. The smaller $C_{\mathrm{m}}$ is comparable to that measured in early postnatal $\mathrm{IHCs}^{14}$. The resting membrane potential $\left(V_{\mathrm{m}}\right)$ remained relatively constant as a function of age $\left(V_{\mathrm{m}}\right.$ : Fig. $\left.5 \mathrm{i}\right)$. This is because the main $\mathrm{K}^{+}$ current contributing to the resting $V_{\mathrm{m}}$ in IHCs is $I_{\mathrm{K}, \mathrm{n}}$ in adult Myo7aflfl mice and $I_{\mathrm{K} 1}$ in pre-hearing and "adult" Myo7afl ${ }^{f}$ Myo15-cre ${ }^{+/-}$mice. The in vivo consequence of this progressive regression in IHC maturity was that while at P15 Myo7afl/ ${ }^{\prime} l_{M y o 15-c^{+l-}}$ mice had normal hearing thresholds (Fig. 4j), they were profoundly deaf at P62 (Supplementary Fig. 6). Adult Myo7aflfl Myo15-cre ${ }^{+1-}$ mice also exhibit the classical head bobbing and hyperactive circling behavior characteristic of Myo7a mutant mice ${ }^{32}$. Both Myo7a $a^{f l f l}$ and Myo15-cre ${ }^{+/-}$mice showed normal hearing thresholds (Supplementary Fig. 6).

The MET current ensures that IHCs retain adult $\mathrm{K}^{+}$currents. To confirm the hypothesis that the resting MET current is required for IHCs to maintain their mature biophysical characteristics, we set up organotypic cultures from the adult cochlea. For these experiments we used gerbils (P18-P24), instead of mice, because their adult IHCs are more robust and can survive in vitro for the long periods required to test the hypothesis. Initially, cochleae were cultured for 1 to 8 days in the DMEM/F12 medium supplemented with $\mathrm{CaCl}_{2}$ (final concentration: $1.3 \mathrm{mM} \mathrm{Ca}{ }^{2+}$, see Methods). Compared to IHCs recorded from acutely dissected gerbil cochleae (P21-P28: Fig. 6a, f), cells under the above culturing conditions gradually lost $I_{\mathrm{K}, \mathrm{f}}$, the most distinctive current expressed in post-hearing IHCs (Fig. $6 \mathrm{~b}, \mathrm{c}, \mathrm{f}$ ). By the $5^{\text {th }}$ day in culture, $I_{\mathrm{K}, \mathrm{f}}$ was no longer present in IHCs while a large $I_{\mathrm{K}}$ was evident (Fig. $6 \mathrm{c}, \mathrm{f}$ ). The main differences between the in vivo and our in vitro culture conditions, is that in the latter the IHC stereociliary bundles are not stimulated by sound, the endocochlear potential is absent and the resting open probability of the MET channel is very low because of the high extracellular $\mathrm{Ca}^{2+}$ concentration $(1.3 \mathrm{mM})^{4}$. Therefore, in vitro, only a very small or no depolarizing inward MET current is likely to be present ${ }^{5,8}$. By keeping IHCs depolarized using high $\mathrm{K}^{+}$in the culture medium $(40 \mathrm{mM})$, as a proxy for the in vivo receptor potential caused by the resting MET current, $I_{\mathrm{K}, \mathrm{f}}$ was retained for longer periods (Fig. 6d, e, f). The direct contribution of the resting MET current in maintaning the adult IHC biophysical identity was tested by using a medium containing the expected in vivo mature endolymphatic $\mathrm{Ca}^{2+}(40 \mu \mathrm{M})$, which substantially increases the resting MET current ${ }^{4,27}$. In $40 \mu \mathrm{M} \mathrm{Ca}^{2+}$ (Fig. $6 \mathrm{~g}, \mathrm{~h}, \mathrm{k}$ ), the size of $I_{\mathrm{K}, \mathrm{f}}$ was significantly higher compared to that measured in $1.3 \mathrm{mM} \mathrm{Ca}^{2+}$ (Fig. 6b, c, k; $P=0.006$, two-way ANOVA) or when $40 \mathrm{mM} \mathrm{K}^{+}$ was used (Fig. 6d, e, f: $P=0.0166$, two-way ANOVA). When cochlear cultures were incubated with $40 \mu \mathrm{M} \mathrm{Ca}^{2+}$ together with $50 \mu \mathrm{M}$ of the MET channel blocker d-tubocurarine ${ }^{33,34}$ (Fig. 6i, j, l), which has been shown to be non-toxic to IHCs in long-lasting cochlear cultures ${ }^{34}$, IHCs showed a strongly reduced $I_{\mathrm{K}, \mathrm{f}}$ (Fig. 6k) compared to when $40 \mu \mathrm{M} \mathrm{Ca}^{2+}$ was used alone (Fig. $6 \mathrm{k}, P=$ 0.0001 , two-way ANOVA), but produced similar results to when the open probability of the MET channel was very low (1.3 mM Ca ${ }^{2+}$, black circles: Fig. 6k, $P=0.6155$, two-way ANOVA). Blocking the MET channel caused IHCs not only to rapidly lose $I_{\mathrm{K}, \mathrm{f}}$ but also to express the inward rectifier $\mathrm{K}^{+}$ current $I_{\mathrm{K} 1}$, which is normally present in pre-hearing cells ${ }^{16}$ (Fig. 61). $I_{\mathrm{K} 1}$ was already evident in 4-day cultured IHCs and became larger over time $(253 \pm 54 \mathrm{pA}, n=13, \mathrm{P} 18-\mathrm{P} 26+$ 4-8 days). Although $I_{\mathrm{K} 1}$ was also seen in IHCs with partially closed MET channels $\left(1.3 \mathrm{mM} \mathrm{Ca}^{2+}: 103 \pm 22 \mathrm{pA}, n=7, \mathrm{P} 18+\right.$ 8 days) it was significantly smaller than that measured in the presence of $40 \mu \mathrm{M} \mathrm{Ca}^{2+}$ and d-tubocurarine (P18 +8 days: $393 \pm$ $153 \mathrm{pA}, n=4, P=0.0324$, $t$ - test).

Normal efferent innervation requires the MET current. Synaptic activity or exocytosis is known to change between preand post-hearing IHCs in terms of $\mathrm{Ca}^{2+}$-efficiency ${ }^{12}$. Presynaptic activity was estimated by measuring the size of the $\mathrm{Ca}^{2+}$ current $\left(I_{\mathrm{Ca}}\right)$ and the induced increase in cell membrane capacitance $\left(\Delta C_{\mathrm{m}}\right)$ following depolarizing voltage steps ${ }^{12} . I_{\mathrm{Ca}}$ in IHCs from both young adult $(-191 \pm 21 \mathrm{pA}, n=8,3$ mice, P16-P17) and adult $\left(-158 \pm 12 \mathrm{pA}, n=5,3\right.$ mice, P48) Myo $7 a^{\text {fl/fl }}$ Myo15-cre ${ }^{+/-}$ mice was not significantly different $(P=0.1252$, one-way ANOVA) to those measured in control Myo7afl/fl IHCs $\left(I_{\mathrm{Ca}}\right.$ : $-156 \pm 13 \mathrm{pA}, n=5,2$ mice, P16-P17; $-129 \pm 5 \mathrm{pA}, n=4,3$ mice, P49) (Fig. $7 \mathrm{a}-\mathrm{d}$ ). In addition, the corresponding $\Delta C_{\mathrm{m}}$ was also similar between $M y o 7 a^{f l / f l} M y o 15-\mathrm{cre}^{+/-}(17.5 \pm 1.9 \mathrm{fF}, n=8$, P16-P17; $14.6 \pm 1.0 \mathrm{fF}, n=5, \mathrm{P} 48)$ and control Myo7afl/fl IHCs $(17.4 \pm 4.6 \mathrm{fF}, n=5$, P16-P17; $13.6 \pm 0.7 \mathrm{fF}, n=4, \mathrm{P} 49 ; P=0.652$, one-way ANOVA). The apparent larger inactivation of $I_{\mathrm{Ca}}$ in 
a

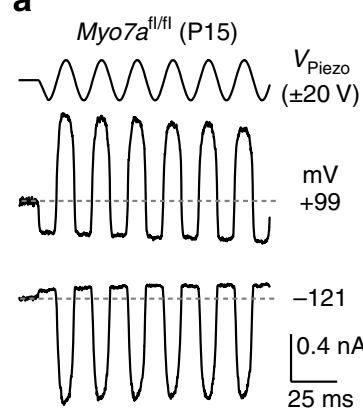

d
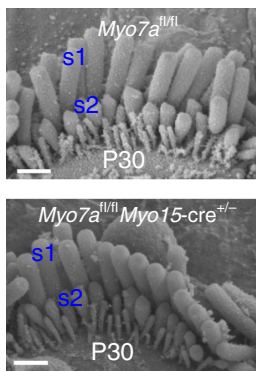

Myo7a $\mathrm{a}^{\mathrm{fl} / \mathrm{fl}}$ Myo 15-cre

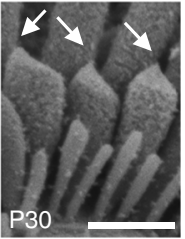

e
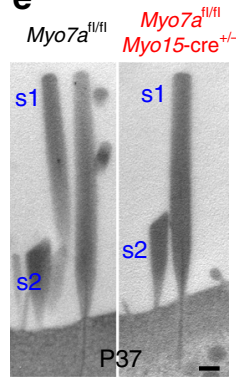

b

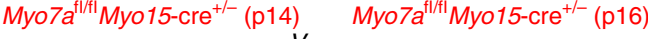

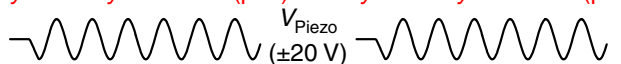
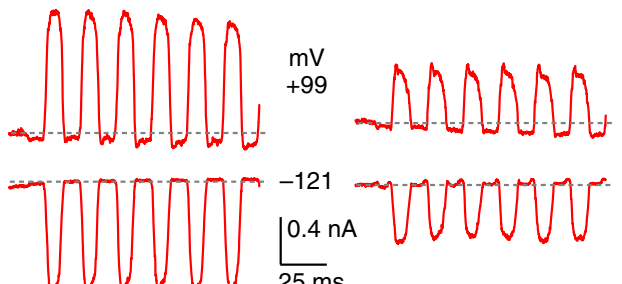

C

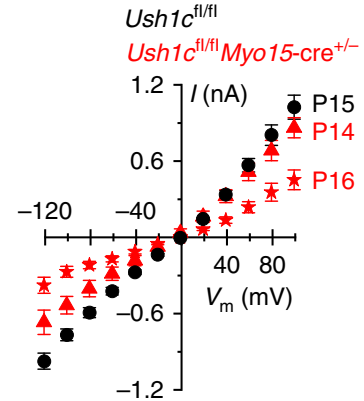

f
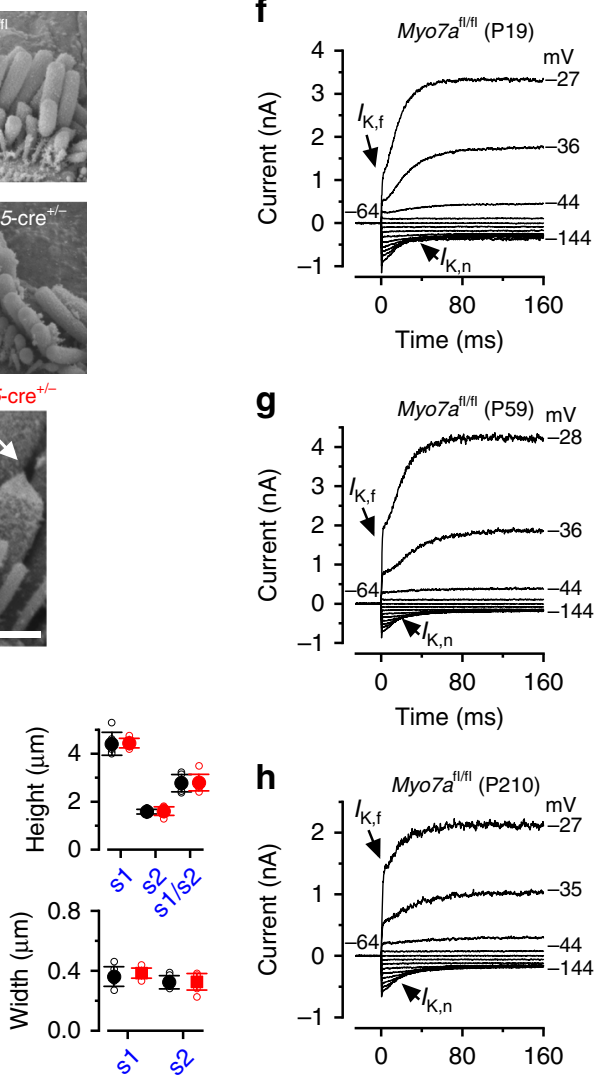

h

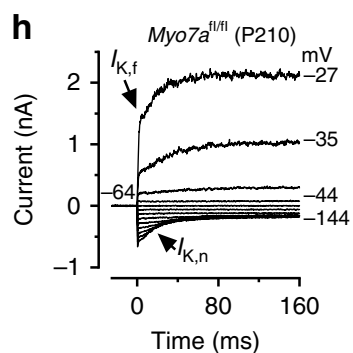

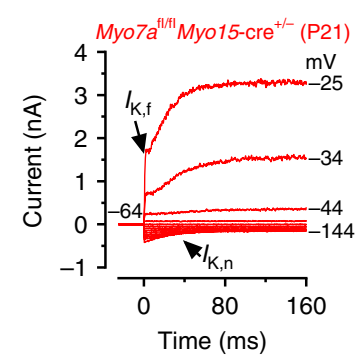

i
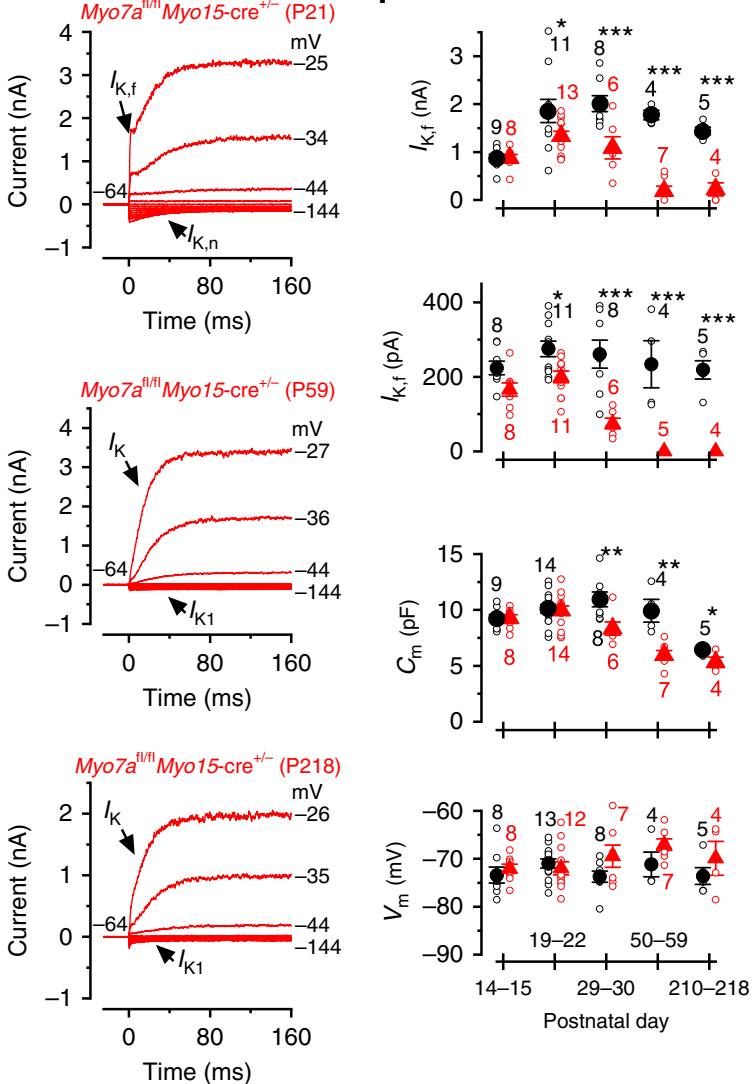

Fig. 5 The functional MET current is required for retaining mature IHC characteristics. a, b MET currents recorded from mature IHCs of control Myo7a $f^{f l / f l}$ (a, P15) and Myo7a $a^{f / / f l}$ Myo15-cre ${ }^{+/-}$(b, P14 and P16) mice. Protocol as in Fig. 2a. c Peak-to-peak MET current-voltage curves obtained from six P15 Myo7afl fl (2 mice), four P14 Myo7afl/flMyo15-cre ${ }^{+/-}$and six P16 Myo7afl/flMyo15-cre $+/$IHCs (3 mice). d Scanning electron microscopy images showing the

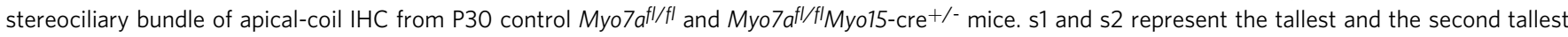
stereocilia, respectively. The arrows in the middle panel highlights that tip links, which are required to gate the MET current, are present in Myo7a $a^{f l / f l} \mathrm{Myo} 15-$ $\mathrm{cre}^{+/-} \mathrm{IHCs}$. Scale bars, $1 \mu \mathrm{m}$. e Transmission electron microscopy images (left) showing the stereocilia s1 and s2 (see panel d) of apical-coil IHCs from

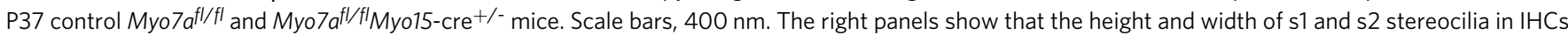
are comparable between the two genotypes (Myo7a $\mathrm{a}^{\mathrm{fl} / \mathrm{fl}} \mathrm{s}$ : height $4.42 \pm 0.48 \mu \mathrm{m}$, width $0.36 \pm 0.07 \mu \mathrm{m}, n=6 \mathrm{IHCs}$, s2: height $1.58 \pm 0.10 \mu \mathrm{m}$, width $0.32 \pm 0.04 \mu \mathrm{m}, n=7, \mathrm{~s} 1 / \mathrm{s} 2: 2.77 \pm 0.36, n=6 ;$ Myo7 $\mathrm{a}^{f l / f l}$ Myo15-cre ${ }^{+/-} \mathrm{s} 1: 4.44 \pm 0.20 \mu \mathrm{m}, P<0.8915,0.38 \pm 0.03 \mu \mathrm{m}, P<0.4441, n=7, \mathrm{~s} 2: 1.61 \pm 0.18$ $\mu \mathrm{m}, P<0.7849,0.33 \pm 0.06 \mu \mathrm{m}, P<0.8959, n=7, \mathrm{~s} 1 / \mathrm{s} 2: 2.80 \pm 0.35, P<0.9059, n=6)$. f-h Potassium currents recorded from IHCs of young adult (f, P19 and P21), adult (g, P59) and aged (h, P210 and P218) control Myo7a $a^{f l / f l}$ (left panels) and Myo7afl/fl Myo15-cre ${ }^{+/-}$(right panels) mice. Protocols are as in Fig. 3a. i Size of $I_{K, f}, l_{K, n}$, membrane capacitance $\left(C_{m}\right)$ and resting membrane potential $\left(V_{m}\right)$ as a function of postnatal age. Number of IHC investigated is shown above or below the symbols (for more details see Supplementary Table 3). Statistical tests are performed with two-way ANOVA with Bonferroni correction. Average data is shown as mean \pm SEM $(\mathbf{c}, \mathbf{i})$ or mean \pm SD (e)

Myo7aflfl Myo15-cre $a^{+/-}$IHCs (Fig. 7c) was due to the activation of the SK2 current (see also Fig. 7f), which is characteristic of prehearing $\mathrm{IHCs}^{35,36}$.

In the adult mammalian cochlea, the efferent fibers either form axo-somatic synapses with OHCs or axo-dendritic synapses with the afferent fibers that contact $\mathrm{IHCs}^{37}$. IHCs are directly innervated by cholinergic efferent endings only during early stages of development, but no longer respond to acetylcholine (ACh) from about P18 onwards ${ }^{35,36,38}$. Adult IHCs from P22 Myo7afl/fl and Myo7aflfl Myo15-cre ${ }^{+/-}$mice did not respond to extracellular ACh (Fig. 7g; Supplementary Fig. 7a, b) and no longer showed axo-somatic efferent contacts at P20 

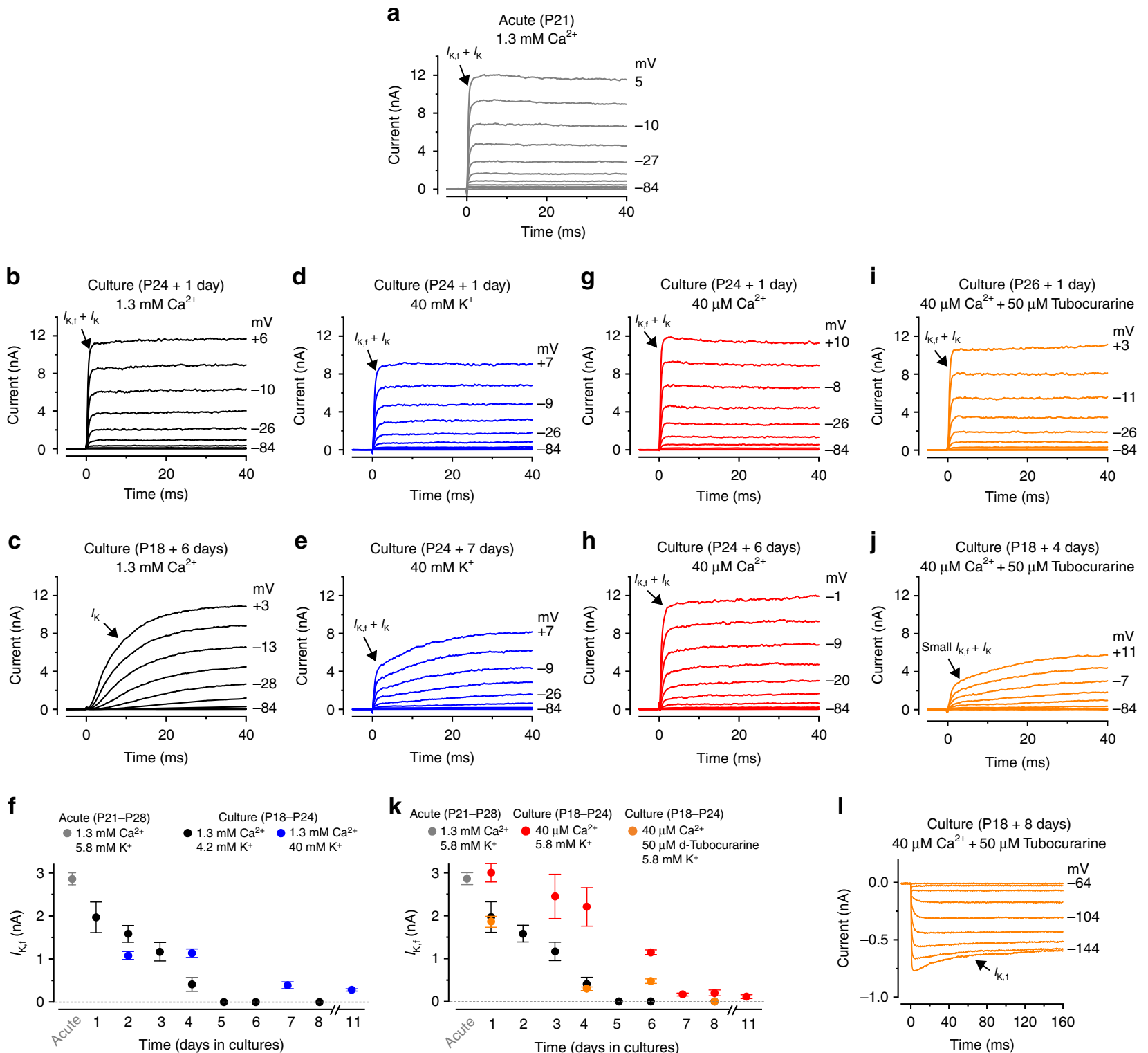

Fig. 6 The resting MET current drives the maintenance of mature $\mathrm{IHC} \mathrm{K}{ }^{+}$currents in cochlear cultures. a Potassium outward currents recorded from a P21 $\mathrm{IHC}$ of an acutely dissected gerbil cochlea. Recordings were performed using a perilymph-like solution ( $1.3 \mathrm{mM}$ extracellular $\left.\mathrm{Ca}^{2+} ; 5.8 \mathrm{mM} \mathrm{K}{ }^{+}\right)$. Currents were elicited using $10 \mathrm{mV}$ depolarizing voltage steps from $-84 \mathrm{mV}$. Note the fast activating $I_{\mathrm{K}, \mathrm{f}}$ characteristic of adult IHCs (arrow). b, c Currents recorded from IHCs maintained in cochlear culture for 1 day (b) or 6 days (c). The culture medium bathing the cochlea (see Methods) contained $1.3 \mathrm{mM} \mathrm{Ca}^{2+}$ and $4.2 \mathrm{mM} \mathrm{K}^{+}$. d, e Currents recorded from IHCs maintained in culture for 2 day (d) or 7 days (e). Culture medium contained $1.3 \mathrm{mM} \mathrm{Ca}{ }^{2+}$ and $40 \mathrm{mM} \mathrm{K}{ }^{+}$. f Size of $I_{K, f}$ recorded from IHCs of acutely isolated gerbil cochleae (gray circle, $n=6$, P21-P28, 3 gerbils) or maintained in culture. Culture conditions were: (1) normal medium (black circles, number of IHCs from left to right: 7,3,4,10,2,6,7; from 9 cochlear cultures; gerbil age at the day of culturing: P18-P24); 2) medium supplemented to $40 \mathrm{mM} \mathrm{K}^{+}$(blue circles, number of IHCs: 6,6,5,7, from 4 cochlear cultures, P18-P24). g, h Currents recorded from IHCs maintained in culture for 1 day ( $(\mathbf{g})$ or 6 days (h) with a medium containing $40 \mu \mathrm{M} \mathrm{Ca}^{2+} \mathbf{i}, \mathbf{j}$, I Currents from IHCs maintained in cochlear culture for 1 day (i), 4 days (j) or 8 days (I) with a medium containing $40 \mu \mathrm{M} \mathrm{Ca}^{2+}$ and $50 \mu \mathrm{M}$ of the MET channel blocker d-tubocurarine. The inward rectifier $\mathrm{K}^{+}$current $\left(I_{\mathrm{K} 1}\right)$ I was obtained using $10 \mathrm{mV}$ hyperpolarizing voltage steps from $-64 \mathrm{mV}$. $\mathbf{k}$ Size of $I_{\mathrm{K}, \mathrm{f}}$ recorded from IHCs of acutely dissected cochleae (gray circle: same as in panel f), maintained in culture with a normal medium (black circles: as in panel f), a medium containing $40 \mu \mathrm{M} \mathrm{Ca}{ }^{2+}$ (red circles: number of IHCs: 5,10,9,5,3,5,8, from 9 cochlear cultures, P18-P24) and a medium containing $40 \mu \mathrm{M} \mathrm{Ca}{ }^{2+}$ and $50 \mu \mathrm{M}$ d-tubocurarine (orange circles: 4,6,6,4, from 4 cochlear cultures, P18-P24). Average data is shown as mean \pm SEM

(Supplementary Fig. 7c, d), indicating that the re-wiring of maturing IHCs occurred normally. However, at older ages (P33P49), while IHCs from control Myo7aflfl mice remained insensitive to ACh (Fig. 7e), those from Myo7afl/fl Myo15-cre ${ }^{+/-}$ mice responded with an instantaneous current (Fig. 7f) that increased the slope conductance at $-84 \mathrm{mV}(P=0.0045, t$ - test, Fig. $7 \mathrm{~g}$ ). In pre-hearing IHCs the ACh-dependent current is mediated by $\mathrm{Ca}^{2+}$ entering through $\alpha 9 \alpha 10$ nAChRs, which then activates SK2 channels ${ }^{35,36}$. Both currents components were observed when ACh was applied to Myo7a fl/fl Myo15-cre ${ }^{+/-}$IHCs (Fig. 7f), with the outward current mainly carried by SK2 channels and the inward relaxing current most likely due to cations entering the IHC through $\alpha 9 \alpha 10$ nAChRs from the holding potential of $-84 \mathrm{mM}^{35}$. 

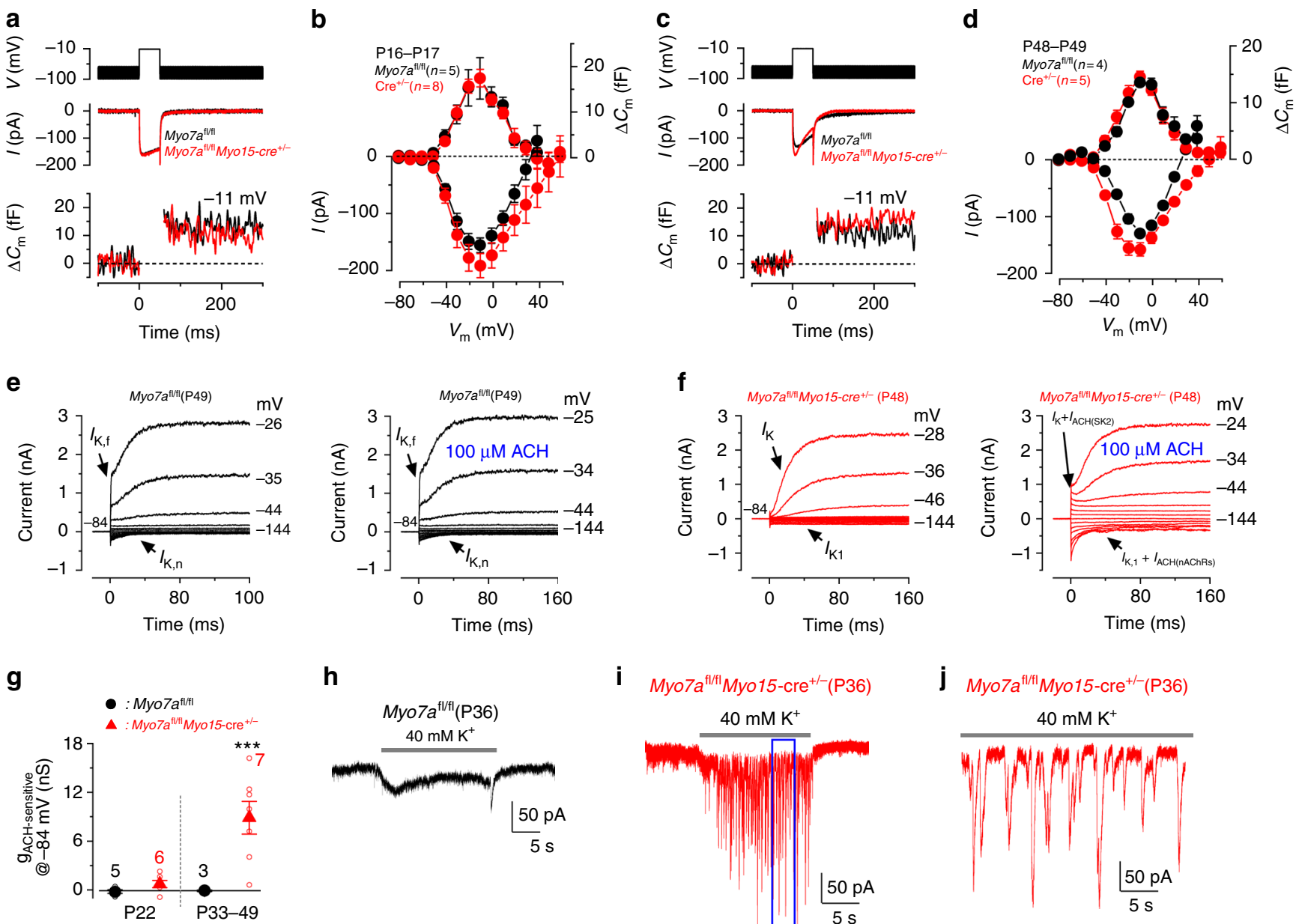

\section{h}

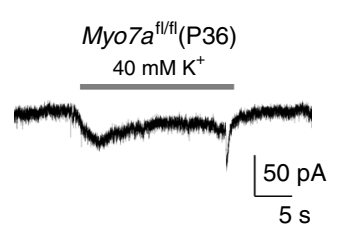

i

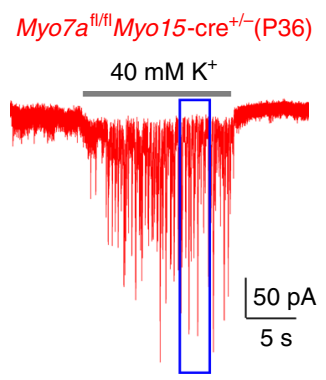

j $M y 07 a^{\mathrm{f} / / 1 / 1} M y 015-\mathrm{cre}^{+/-}(\mathrm{P} 36)$

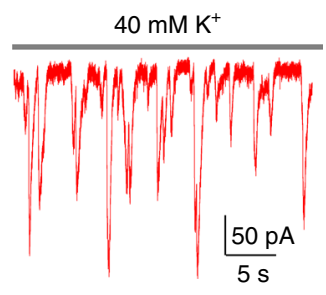

$\mathbf{k}$
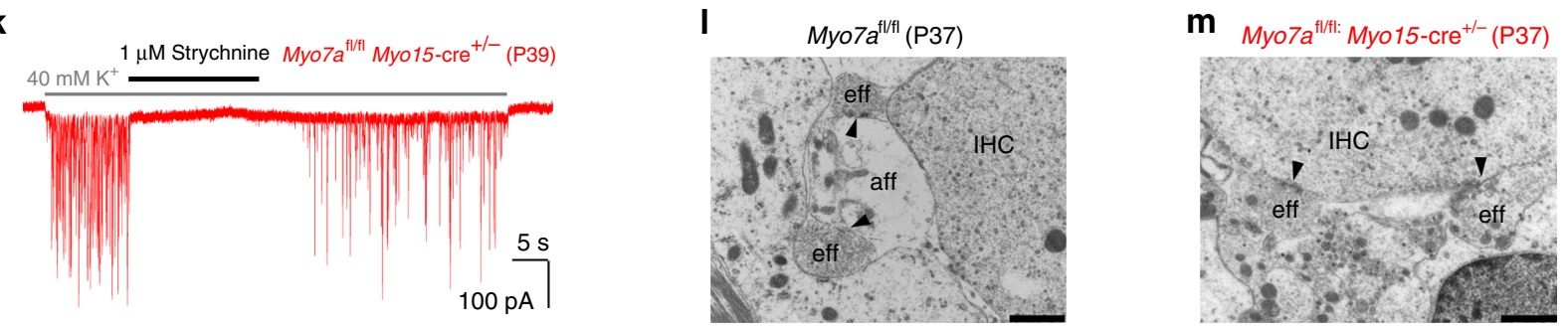

Fig. $7 \mathrm{IHC}$ exocytosis is unaffected in adult Myo7a $\mathrm{a}^{\mathrm{fl} / \mathrm{fl} / \mathrm{Myo} 15-\mathrm{cre}} \mathrm{T}^{+/-}$mice but efferent input is altered. a-d Calcium current $\left(I_{\mathrm{Ca}}\right)$ and corresponding changes in membrane capacitance $\left(\Delta C_{m}\right)$ recorded from IHCs of P16-P17 $(\mathbf{a}, \mathbf{b})$ and P48-P49 (c, d) control Myo7afl/fl (black) and knockout Myo7afl/fl Myo15-cre ${ }^{+/-}$ mice (red). Recordings were obtained in response to $50 \mathrm{~ms}$ voltage steps ( $10 \mathrm{mV}$ increments) from $-81 \mathrm{mV}$ and using $1.3 \mathrm{mM}$ extracellular $\mathrm{Ca}{ }^{2+}$ and at body temperature. For clarity, only maximal responses at $-11 \mathrm{mV}$ are shown. Panels $\mathbf{b}$ and $\mathbf{d}$ shows average peak $I_{\mathrm{Ca}}$ (bottom) and $\Delta C_{\mathrm{m}}$ (top) curve from control Myo7a $a^{f / / f l}$ and Myo7afl/fl Myo15-cre ${ }^{+/-}$IHCs. e, f Membrane currents recorded from adult IHCs of control Myo7a $a^{f l / f l}$ (e) and Myo7afl/fl Myo15-cre ${ }^{+/-}$ (f) mice before (left panels) and during superfusion of ACh (right panels). ACh elicited an instantaneous current only in the $M y 07 a^{f l / f l}$ Myo15-cre ${ }^{+/-}$IHC.

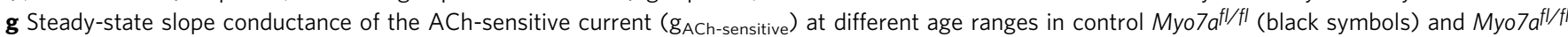

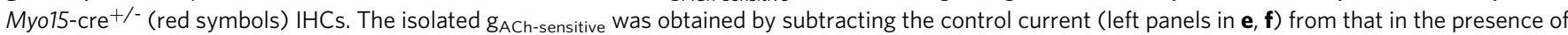

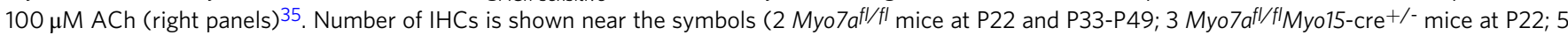
Myo7a fl/fl Myo15-cre $+/$ mice at P34-P48). h-k Voltage-clamp recordings obtained from adult IHCs of control Myo7a $a^{f l / f l}(\mathbf{h}, \mathrm{P36})$ and Myo7afl/fl Myo15-cre ${ }^{+/-}$ $\left(\mathbf{i}, \mathbf{j}\right.$, P36; k P39) mice during the superfusion of $40 \mathrm{mM}$ extracellular $\mathrm{K}^{+}$. Synaptic currents were only evoked in Myo7a ${ }^{f / / f l} \mathrm{Myo} 015-\mathrm{cre}^{+/ /}$IHCs. Panel $\mathbf{j}$ shows an expanded time scale of the blue area shown in panel (i). Panel $\mathbf{k}$ shows the effect of $1 \mu \mathrm{M}$ strychnine on the ACh-induced synaptic currents. I, $\mathbf{m}$ TEM showing the IHC synaptic region from P37 control Myo7afl/fl (I) and Myo7a fl/flMyo15-cre ${ }^{+/-}$(m) mice. IHCs from Myo7afl/fl mice showed the characteristic synaptic organization of mature cells with efferent terminals forming axo-dendritic contact with the afferent fibers, as seen by the presence of active zones (I, black arrows). Scale bars, $1 \mu \mathrm{m}$. In Myo7a $a^{f / / f l}$ Myo15-cre ${ }^{+/-}$mice efferent fibers make direct axo-somatic contact with the IHC (m), which is characteristic of pre-hearing IHCs. Average data is shown as mean $\pm \mathrm{SEM}$ 
In order to establish whether re-appearance of ACh receptors in adult $M y o 7 a^{f l / f l} M y o 15-c^{+/-}$IHCs was associated with reestablishment of axosomatic efferent synapses, we perfused the cochlea with a solution containing $40 \mathrm{mM} \mathrm{KCl}$. High $\mathrm{K}^{+}$ is expected to depolarize the efferent synaptic terminals and trigger the release of ACh-containing vesicles, which generate synaptic currents in IHCs superimposed upon a sustained inward current due to the direct effect of $\mathrm{KCl}$ on the cell's basolateral membrane ${ }^{38,39}$. Synaptic inward currents were only seen in Myo7afl/fl Myo15-cre ${ }^{+-}$IHCs (Fig. $\left.7 \mathrm{~h}-\mathrm{j}\right)$, with a frequency $(5.7 \pm$ $0.7 \mathrm{~Hz}, 715$ events, $n=7,4$ mice) and amplitude (98 \pm 19 pA, 594 events, $n=7$ ) not significantly different from those previously reported in pre-hearing IHCs $(P=0.68$ and $P=0.107, t$-test, respectively $)^{39}$. Reversible block of the ACh-mediated currents by $1 \mu \mathrm{M}$ strychnine (Fig. 7k), a potent blocker of $\alpha 9 \alpha 10 \mathrm{nAChRs}^{40}$, confirmed the re-expression of these receptors in adult Myo7afl/fl Myo15-cre ${ }^{+/-}$IHCs. TEM experiments on P37 mice ( $\geq 3$ mice for each genotype) indicated that while IHCs from $M y o 7 a^{f l / f l}$ mice showed the characteristic axo-dendritic contacts between efferent and afferent fibers (Fig. 7l), Myo $7 a^{f l / f l}$ Myo15-cre ${ }^{+/-}$mice underwent major re-wiring with efferents re-forming direct axosomatic innervation with adult IHCs (Fig. $7 \mathrm{~m}$ ).

\section{Discussion}

Here we show that the MET current is essential to establish and maintain the key biophysical and morphological properties characteristic of adult IHCs. During the second post-natal week in mice, which is just before the onset of hearing at P12, open MET channels keep the IHC membrane potential at the threshold for $\mathrm{Ca}^{2+}$ action potentials (APs), promoting their functional differentiation into mature graded sensory receptors able to encode sound stimuli. We also found that adult IHCs require functional MET channels to maintain their adult profile. The absence of the MET current during adult stages caused IHCs to lose their identity, regressing into an immature-like biophysical and morphological profile. Adult IHCs without functional MET channels became re-innervated by inhibitory cholinergic efferent neurons, which normally make transient axo-somatic contacts only with pre-hearing IHCs.

Pre-hearing IHCs of altricial rodents exhibit spontaneous $\mathrm{Ca}^{2+}$-dependent $\mathrm{APs}^{5,10,14}$ that can be modulated by the inhibitory efferent neurotransmitter $\mathrm{ACh}^{38}$ and by excitatory spontaneous ATP-induced $\mathrm{Ca}^{2+}$-waves in non-sensory cells, which synchronize the activity of several IHCs ${ }^{10,28,41}$. Indeed, patterned bursts of APs have been recorded from auditory afferent neurons prior to the onset of hearing in mice ${ }^{42,43}$, and both their survi$\mathrm{val}^{11}$ and the refinement of tonotopic maps in the auditory brainstem ${ }^{13,44}$ rely on the firing activity of pre-hearing IHCs. However, the refinement of the auditory pathway mainly occurs during the first postnatal week ${ }^{11,44,45}$, a finding supported by evidence that surgical removal of the cochlea causes a substantial loss of cochlear nucleus neurons mainly during this period ${ }^{46,47}$. Despite the crucial role of APs in developing IHCs, spiking activity is not suitable to detect sound because it would modulate and degrade auditory stimuli in the mature cochlea. Therefore, just before hearing onset immature IHCs undergo major changes involving the acquisition and/or elimination of different ion channels and other membrane proteins ${ }^{9,12,14}$. Intracellular $\mathrm{Ca}^{2+}$ transients associated with a precise frequency and/or pattern of AP activity can activate transcription factors controlling the expression of proteins linked to development ${ }^{48,49}$. In cochlear IHCs, repetitive $\mathrm{Ca}^{2+}$ APs during the second postnatal week are driven by a standing depolarizing MET current ${ }^{5}$, resulting from the progressive reduction in endolymphatic $\mathrm{Ca}^{2+}$ concentration ${ }^{5}$ that, by reducing adaptation, increases the MET channel open probability. Therefore, AP activity driven by the greater standing MET current during the few days preceding hearing onset could provide the cue or trigger for the last step of IHC development by influencing gene expression. We demonstrate that genetic manipulations that abolish the contribution of the MET current in vivo during the second postnatal week prevented IHCs from becoming mature auditory receptors. We propose that, during pre-hearing stages of development, the primary function of IHC AP activity could switch from refining the auditory circuitry ${ }^{13}$ to promoting the maturation of the sensory receptor itself.

The normal AP activity in IHCs from pre-hearing Myo7afl/ ${ }^{f}$ Myo15-cre ${ }^{+/-}$mice meant that their auditory system was able, at least initially, to mature fully as judged by the presence of normal ABRs (P15), absence of axo-somatic efferent terminals on P20P22 IHCs, and a normal IHC basolateral current profile at P20. However, the loss of IHC MET current after the onset of hearing caused a progressive down-regulation of the adult-type basolateral ion channels carrying $I_{\mathrm{K}, \mathrm{f}}$ and $I_{\mathrm{K}, \mathrm{n}}$. By two months of age, IHCs from Myo7afl/fl Myo15-cre ${ }^{+/-}$mice have the same size and basolateral membrane currents as pre-hearing cells, including the re-expression of $I_{\mathrm{K} 1}{ }^{16}$ and $I_{\mathrm{SK} 2}{ }^{35,36}$. A similar progressive loss of $I_{\mathrm{K}, \mathrm{f}}$ was also observed in cultured cochlear IHCs, in which cells are not stimulated by sound and the resting open probability of the MET current is either reduced or blocked. In vitro experimental manipulations that increased the MET channel open probability (endolymphatic-like $\mathrm{Ca}^{2+}$ concentration) or mimicked the receptor potential due to sound stimulation (IHC depolarization) were able to maintain the adult current profile of cultured IHCs for longer. Calcium entering via the MET channel has been shown to be required for maintaining the morphological stability of transducing stereocilia in early postnatal hair cells ${ }^{50}$. Although in the presence of mature endolymphatic-like solution $\mathrm{Ca}^{2+}$ entering through the MET channel seems to be cleared from the stereocilia by the plasma membrane $\mathrm{Ca}^{2+}$ ATPase type 2 (PMCA2), some of it could diffuse into the cell body ${ }^{51}$ and, together with the depolarization by the MET current, potentially regulate gene expression and as such the maintenance of the adult IHC current profile. The only adult-like function that was not affected by the loss of the MET channel was that associated with the synaptic machinery, indicating that once it has matured, a process that is controlled by a critical period of pre-hearing $\mathrm{APs}^{12}$, it becomes independent of IHC activity. Loss of ribbon synapses in the adult cochlea occurs following acoustic trauma or ototoxic antibiotics ${ }^{52}$, conditions that cause either a temporary or permanent IHC damage. IHCs from aging mice have also been shown to gradually lose ribbon synapses ${ }^{53}$. The fact that exocytosis in IHCs from Myo7aflfl Myo15-cre ${ }^{+/-}$mice was normal at 7 weeks, despite IHCs starting to become smaller, may be due to ribbon loss being a slow process ${ }^{53}$.

While auditory ribbon synapses appeared to be resilient to post-maturational changes in MET function, the efferent fibers were more plastic. The efferent endings make transient cholinergic axo-somatic contacts with immature $\mathrm{IHCs}^{54,55}$. After the onset of hearing, efferent terminals only form axo-dendritic synapses with the auditory afferent fibers contacting $\mathrm{IHCs}^{56}$ and expression of the postsynaptic a9nAChRs and SK2 channels is rapidly down-regulated ${ }^{54}$. Therefore, adult IHCs lose the ability to respond to $\mathrm{ACh}^{38,54}$. However, it has been shown that efferent endings can re-innervate IHCs following cochlear damage ${ }^{57}$ or in aging mice $\mathrm{e}^{53,58}$. We found that the re-emergence of axo-somatic efferent innervation with IHCs can also occur in mature mice with no functional MET current.

The above findings, including the reduced size of the IHCs, the direct re-innervation by efferent cholinergic fibers, the complete down-regulation of the adult-like basolateral membrane ion channels and the ability to fire APs, indicate that functional MET 
channels are required for mature IHCs to maintain their biophysical and morphological identity. Without functional MET channels, IHCs revert to an earlier, pre-hearing stage of development. It would be interesting in the future to determine whether the re-establishment of the immature-like biophysical and morphological profile in IHCs without working MET channels is the first stage of an intrinsic attempt to repair the faulty cochlea by "recapitulating" early development. In any case, this functional regression shows a surprising plasticity in the mature cochlea in response to events that abolish normal MET currents, which could occur due to either noise ${ }^{59,60}$, aging ${ }^{61}$ or in forms of progressive hearing loss, such as Usher syndrome type III $^{62}$.

\section{Methods}

Ethics statement. All animal studies were performed in the UK and licensed by the Home Office under the Animals (Scientific Procedures) Act 1986 and were approved by the University of Sheffield and University of Sussex Ethical Review Committees. ABR measurements (see below) were conducted under anesthesia using ketamine $(100 \mathrm{mg} / \mathrm{Kg}$, Fort Dodge Animal Health) and xylazine $(10 \mathrm{mg} / \mathrm{Kg}$, Rompun $2 \%$, Bayer), which were administered with intraperitoneal injection as previously described ${ }^{63}$. At the end of the experiments, which lasted up to 40 minutes, mice were usually culled by a schedule 1 method. In a few animals, ABR measurements were followed by the recovery of the mice from anesthesia with intraperitoneal of atipamezole mix $^{63}$.

Animal strains. For the conditional knockout mice, the targeted tm1 $a$ allele for

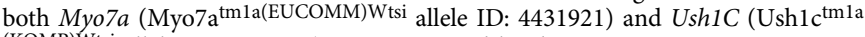
(KOMP)Wtsi allele ID: 4363497) were generated by the Mouse Genetics

Programme at the Wellcome Trust Sanger Institute (Cambridge, UK). For Myo7a the critical exons 10 and 11 were floxed, while for Ush1c exons 5-8 were floxed. The tm1c allele was obtained by crossing the tm1a mouse to a FLPeR carrying mouse (Rosa26 $6^{\mathrm{Fki}}$ ). The $t m 1 d$ alleles, which were used for the experiments, were obtained by crossing the tmic mouse (Myo7afl/fl and Ush $1 c^{f l / f l}$ ) with the Myo15-cre mice and genotyped as previously described ${ }^{24}$. The genotyping protocols for mutant mice were also previously described: Myo7a (Myo7ash6/sh66) $)^{31}$ and $P c d h 15\left(P c d h 15^{a v 3 J}\right)^{15}$. For the conditional knockout mice (tm1c alleles) genomic DNA was amplified under standard reaction conditions using Promega Taq DNA polymerase (Invitrogen, UK). The reaction mix was incubated at $94^{\circ} \mathrm{C}$ for $5 \mathrm{~min}$ followed by 40 cycles of $94^{\circ} \mathrm{C}$ for $30 \mathrm{~s}, 58^{\circ} \mathrm{C}$ for $45 \mathrm{~s}$ and $72^{\circ} \mathrm{C}$ for $90 \mathrm{~s}$, followed by $72^{\circ} \mathrm{C}$ for $5 \mathrm{~min}$. Primer pairs and product size are as follows: $M y o 7 a$ : forward, $5^{\prime}-$ GGGAGAGAAAGCGGGTGTG- $3^{\prime}$ and reverse, $5^{\prime}$ - AAGCTGGACTCTCTGGT GGC-3', producing a 360-bp product for the $\mathrm{WT}$ and a 460 -bp product for the tmlc homozygous mutant; Ush $1 \mathrm{C}$ : forward, 5'-ACAGAGCCGTGGGTTCATTC$3^{\prime}$ and reverse, 5'-GTAATGGAGCTGAGGCAGGG-3', producing a 326-bp product for the WT and a 430-bp product for the tmlc homozygous mutant.

Tissue preparation. Inner hair cells (IHCs) were studied in acutely dissected organs of Corti from postnatal day 7 (P7) to P218 mice and P21-P28 gerbils, where the day of birth is PO. In mice, experiments were performed on IHCs positioned in the apical coil of the cochlea (around $12 \mathrm{kHz})^{64}$. Gerbil IHCs were positioned at a frequency range of $250-420 \mathrm{~Hz}^{65}$. Animals of either sex were killed by cervical dislocation and the organ of Corti dissected in extracellular solution composed of (in mM): $135 \mathrm{NaCl}, 5.8 \mathrm{KCl}, 1.3 \mathrm{CaCl}_{2}, 0.9 \mathrm{MgCl}_{2}, 0.7 \mathrm{NaH}_{2} \mathrm{PO}_{4}, 5.6 \mathrm{D}$-glucose, 10 Hepes- $\mathrm{NaOH}$. Sodium pyruvate $(2 \mathrm{mM})$, amino acids and vitamins were added from concentrates (Fisher). The $\mathrm{pH}$ was adjusted to 7.5 (osmolality $\sim 308$ mmol kg-1). The dissected apical coil of the organ of Corti was transferred to a microscope chamber, immobilized using a nylon mesh fixed to a stainless steel ring and viewed using an upright microscope (Leica DM LFS, Germany or Nikon FN1). Hair cells were observed with Nomarski differential interface contrast optics ( $\times 63$ water immersion objectives). To expose the basolateral surface of the cells, a small tear was made in the epithelium with a suction pipette (tip diameter 3-4 $\mu \mathrm{m}$ ) filled with extracellular solution.

Single-cell electrophysiology. Membrane currents and voltage responses were investigated under whole cell voltage or current clamp, respectively, either at room temperature $\left(20-25^{\circ} \mathrm{C}\right)$ or body temperature $\left(34-37^{\circ} \mathrm{C}\right)$, using Optopatch amplifiers (Cairn Research Ltd, UK). Patch pipettes, with resistances of 2-3 $M \Omega$, were pulled from soda glass capillaries (Harvard Apparatus Ltd, Edenbridge, UK). The shank of the electrode was coated with surf wax (Mr Zoggs Sex Wax, CA, USA) to reduce the electrode capacitative transient. When investigating the basolateral properties of IHCs, the intracellular solution was composed of $(\mathrm{mm}): 131 \mathrm{KCl}, 3$ $\mathrm{MgCl}_{2}, 1$ EGTA-KOH, $5 \mathrm{Na}_{2} \mathrm{ATP}, 5$ Hepes-KOH, $10 \mathrm{Na}$-phosphocreatine ( $\mathrm{pH}$ $7.28,294 \mathrm{mmol} \mathrm{kg}^{-1}$ ). When investigating MET currents or membrane capacitance, a Cs-glutamate intracellular solution was used composed of $(\mathrm{mM})$ : $106 \mathrm{Cs}-$ glutamate, $20 \mathrm{CsCl}$, $3 \mathrm{MgCl}_{2}$, 1 EGTA-CsOH, $5 \mathrm{Na}_{2} \mathrm{ATP}, 0.3 \mathrm{Na}_{2} \mathrm{GTP}$, 5 Hepes$\mathrm{CsOH}, 10 \mathrm{Na}_{2}$-phosphocreatine ( $\mathrm{pH} 7.3,294 \mathrm{mmol} \mathrm{kg}^{-1}$ ). Data acquisition was performed using a Digidata 1440 A with pClamp software 10.0 (Axon Instruments, CA, USA) or a CED Power 1401 with Signal Software (CED, Cambridge, UK). Data were filtered at $2.5 \mathrm{kHz}$ (8-pole Bessel) and sampled at $\geq 5 \mathrm{kHz}$. Origin software (OriginLab, Northampton, MA, USA) was used to perform offline data analysis. Membrane potentials were corrected for the residual series resistance $R_{\mathrm{s}}$ after compensation (usually $80 \%$ ) and liquid junction potential (LJP), which for Csglutamate and $\mathrm{KCl}$ intracellular solutions were $-11 \mathrm{mV}$ and $-4 \mathrm{mV}$, respectively.

When investigating basolateral membrane properties, the size of $I_{\mathrm{K}, \mathrm{f}}$ was measured near $-25 \mathrm{mV}$ and at either $0.7 \mathrm{~ms}$ or $1.0 \mathrm{~ms}$ after the start of the voltage step, while $I_{K, n}$ was measured as the difference between the peak and steady state of the deactivating inward current at $-124 \mathrm{mV}$. Steady-state total currents were measured at $160 \mathrm{~ms}$, at a potential of $0 \mathrm{mV}$ (extrapolated from the current-voltage curves). The holding potentials used for these recordings were set at either $-84 \mathrm{mV}$ or $-64 \mathrm{mV}$ (normally specified in the figure legends).

The presence of inhibitory postsynaptic currents in IHCs, which are caused by the release of ACh-containing vesicles from the efferent terminals, was obtained by superfusing $40 \mathrm{mM}$ extracellular $\mathrm{K}^{+}$in order to depolarize the efferent fibers. Event analysis was performed using the Mini Analysis Program (Synaptosoft Inc., USA) Note that the number of events used to calculate the frequency of inhibitory postsynaptic currents (715 events) was larger than that used for the amplitude (594 events: see Results linked to Fig. 7i-l) since the presence of partially overlapping events prevented the accurate assessment of the baseline.

Real-time changes in membrane capacitance $\left(\Delta C_{\mathrm{m}}\right)$ were performed at body temperature as previously described ${ }^{12}$. Briefly, a $4 \mathrm{kHz}$ sine wave of $13 \mathrm{mV}$ RMS was applied to IHCs from $-81 \mathrm{mV}$, unless otherwise stated, and was interrupted for the duration of the voltage step. The capacitance signal from the Optopatch was filtered at $250 \mathrm{~Hz}$ and sampled at $5 \mathrm{kHz} . \Delta C_{\mathrm{m}}$ was measured by averaging the $C_{\mathrm{m}}$ trace over a $200 \mathrm{~ms}$ period following the voltage step and subtracting the pre-pulse baseline. Data were acquired using pClamp software and a Digidata $1440 \mathrm{~A}$ (Molecular Devices). $\Delta C_{\mathrm{m}}$ experiments were performed in the presence of $30 \mathrm{mM}$ TEA and $15 \mathrm{mM} 4$-AP (Fluka) to block the BK current $\left(I_{\mathrm{K}, \mathrm{f}}\right)^{9}$ and delayed rectifier $\mathrm{K}^{+}$currents $\left(I_{\mathrm{K}}\right.$, previously called $I_{\mathrm{K}, \text { neo }}$ in the case of pre-hearing IHCs and $I_{\mathrm{K}, \mathrm{s}}$ in mature IHCs), and linopirdine ( $80 \mu \mathrm{M}$ : Tocris) to block $I_{\mathrm{K}, \mathrm{n}}{ }^{14}$.

For mechanoelectrical transducer (MET) current recordings, a fluid jet driven by a piezoelectric disc was used to elicit bundle displacement as previously described ${ }^{4}$. The tip of the fluid jet pipette had a diameter of $8-10 \mu \mathrm{m}$ and was positioned at about $8 \mu \mathrm{m}$ from the bundles. Saturating mechanical stimuli were applied using $50 \mathrm{~Hz}$ sinusoids (filtered at $1 \mathrm{kHz}$, 8-pole Bessel) with a driver voltage $\left(V_{\text {Piezo }}\right.$ ) to the fluid jet of $\pm 20 \mathrm{~V}$, with positive deflections moving the stereocilia in the excitatory direction. For some experiments a gravity fed local perfusion system was used to extracellularly apply the estimated endolymph-like solution $(300 \mu \mathrm{M}$ $\left.\mathrm{Ca}^{2+}\right)^{5}$ either alone or with $200 \mu \mathrm{M}$ dihydrostreptomycin (DHS). The resting MET current becomes evident when the MET channels shut off in the inhibitory phase of the stimulus: the holding current minus the current present during inhibitory bundle deflection ${ }^{4}$.

Unless otherwise stated, electrophysiological data was analyzed with PCLAMP software (Molecular Devices) and ORIGIN (Origin Lab, USA).

Auditory brainstem responses. Auditory brainstem responses (ABRs) were recorded from either male or female knockout mice and their littermate controls between P15 and P62. Recordings were performed in a soundproof chamber (MAC-3 Acoustic Chamber, IAC Acoustic, UK) as previously described ${ }^{63}$. Briefly, stimuli were delivered to the ear by calibrated loudspeakers (MF1-S Multi Field Speaker, Tucker-Davis Technologies, USA) placed $10 \mathrm{~cm}$ from the animal's pinna. Sound pressure was calibrated with a low-noise microphone probe system (ER10B + , Etymotic, USA). Experiments were performed using BioSigRZ software driving an RZ6 auditory processor (Tucker-Davis Technologies). Response thresholds were estimated from the resulting ABR waveform and defined as the lowest sound level where any recognizable feature of the waveform was visible. Responses were measured for click and pure tone stimuli of frequencies between 3.0 and $24 \mathrm{kHz}$. Stimulus sound pressure levels were typically $0-95 \mathrm{~dB}$ SPL, presented in steps of $5 \mathrm{~dB}$. The brainstem response signal was averaged over 256 repetitions. Tone bursts were $5 \mathrm{~ms}$ in duration with a $1 \mathrm{~ms}$ on/off ramp time, which was presented at a rate of $42.6 / \mathrm{sec}$

Two-photon confocal $\mathbf{C a}^{2+}$ imaging. For calcium dye loading, acutely dissected cochleae were incubated for $40 \mathrm{~min}$ at $37^{\circ} \mathrm{C}$ in DMEM/F12, supplemented with fluo-4 AM (final concentration $10 \mu \mathrm{M}$; Thermo Fisher Scientific) as recently described ${ }^{66} . \mathrm{Ca}^{2+}$ signals were recorded using a two-photon laser-scanning microscope (Bergamo II System B232, Thorlabs Inc., USA) based on a modelocked laser system operating at $800 \mathrm{~nm}, 80-\mathrm{MHz}$ pulse repetition rate, $<100-\mathrm{fs}$ pulse width (Mai Tai HP DeepSee, Spectra-Physics, USA). Images were captured with a 60x objective (LUMFLN60XW, Olympus, Japan) using a GaAsp PMT (Hamamatsu) coupled with a 525/40 bandbass filter (FF02-525/40-25, Semrock). Images were analyzed off-line using custom built software routines written in Python (Python 2.7, Python Software Foundation) and ImageJ (NIH). $\mathrm{Ca}^{2+}$ signals were measured as relative changes of fluorescence emission intensity $\left(\Delta F / F_{0}\right)$. 
Cochlear culture preparation. Cochlear cultures from P18-P24 gerbils were prepared as described previously ${ }^{1}$. Briefly, cochleae were dissected in HEPES buffered (10 mM, pH 7.2) Hanks' balanced salt solution (HBHBSS), placed onto collagen-coated glass coverslips, fed with $100-150 \mu$ l of medium containing $98 \%$ or 93\% standard Dulbecco's modified Eagle's DMEM/F12 with additional $10 \mathrm{mM}$ HEPES buffer, $2 \%$ or $7 \%$ foetal bovine serum (Biosera, UK) and $10 \mu \mathrm{g} / \mathrm{ml} \mathrm{ampi-}$ cillin (Sigma) and maintained at $37^{\circ} \mathrm{C}$ for up to 11 days. The standard DMEM/ F12 solution containing $4.18 \mathrm{mM} \mathrm{KCl}$ and $1.09 \mathrm{mM} \mathrm{CaCl}_{2}$ (Sigma, UK) was used, additionally supplemented with $\mathrm{KCl}$ or $\mathrm{CaCl}_{2}$ depending on the experiments (see Results and Fig. 6). For the experiments designed to test the effect of the adult endolymphatic-like solution $\left(20-40 \mu \mathrm{M} \mathrm{Ca}^{2+}\right)^{6,67}$ the above medium was buffered with $2.2 \mathrm{mM}$ HEDTA. For the recordings aimed at testing the effect of high extracellular $\mathrm{K}^{+}$, the above medium was supplemented with $1 \mathrm{M} \mathrm{KCl}$ to reach the final desired concentrations ( $15 \mathrm{mM}$ or $40 \mathrm{mM} \mathrm{KCl}$ ). In order to block the MET channels in the presence of the endolymphatic-like solution $(40 \mu \mathrm{M}$ $\mathrm{Ca}^{2+}$ : see above), we used $50 \mu \mathrm{M}$ of the MET channel blocker d-tubocurarine (Tocris, UK).

Immunofluorescence microscopy. Dissected inner ears from Myo7a $a^{f / f l}$ and $M y o 7 a^{\mathrm{f} / \mathrm{fl}} M y o 15-\mathrm{cre}^{+/-}$mice $(n=5$ and $n=8$ mice, respectively) were perfused with $4 \%$ paraformaldehyde in phosphate-buffered saline (PBS) for $45 \mathrm{~min}$ at $4{ }^{\circ} \mathrm{C}$. Cochleas were microdissected, rinsed three times for $10 \mathrm{~min}$, and incubated for $1 \mathrm{~h}$ at room temperature in PBS supplemented with $20 \%$ normal horse serum and $0.3 \%$ Triton X-100. The samples were then incubated overnight with the primary antibody: rabbit anti-myosin $7 \mathrm{a}^{68}(1 / 500)$ in PBS supplemented with $1 \%$ horse serum. The samples were rinsed three times for $10 \mathrm{~min}$ in PBS, and then incubated for $1 \mathrm{~h}$ with ATTO-488-conjugated goat anti-rabbit IgG antibody (Sigma-Aldrich, \#18772, 1:500 dilution). Actin was labeled with ATTO-647N-conjugated phalloidin (Sigma-Aldrich, \#65906, 1:200 dilution). Samples were then mounted in Fluorsave (Calbiochem, USA). The z-stack images were captured with a Zeiss LSM700 confocal microscope equipped with a Plan Apochromat 63X/NA 1.4 oil immersion lens (Carl Zeiss, Jena, Germany)

Scanning electron microscopy (SEM). The auditory bullae were isolated from the heads of the mice and opened to expose the cochleae which were fixed, by intralabyrinthine perfusion using a fine hypodermic needle through the round window. The fixative was $2.5 \%$ glutaraldehyde in $0.1 \mathrm{M}$ cacodylate buffer containing $3 \mathrm{mM}$ calcium chloride ( $\mathrm{pH}$ 7.3). Following perfusion the intact cochleae were immersed in the fixative for $2 \mathrm{~h}$ and then decalcified by immersion in $4.0 \%$ EDTA ( $\mathrm{pH} 7.3$ ) for 2 days at $4{ }^{\circ} \mathrm{C}$. Subsequently the cochleae were dissected under cacodylate buffer to isolate approximately half turn segments of the organ of Corti from apex to base. These organ of Corti segments were post-fixed $(2 \mathrm{~h})$ in cacodylate buffered $1 \%$ $\mathrm{OsO}_{4}$, before processing through the thiocarbohydrazide-Os-repeated procedure ${ }^{69}$, followed by dehydration in an ethanol series and critical point drying. The organ of Corti samples were mounted on SEM support stubs with silver paint and sputter coated with a thin (ca $5 \mathrm{~nm}$ ) layer of platinum before examination in a JEOL 6700 cold field-emission SEM operating at 3 or $5 \mathrm{kV}$. Images are a sample from 3 or more mice for each genotype.

Transmission electron microscopy (TEM). For TEM cochleae were fixed as for SEM but postfixed by immersion for $1 \mathrm{~h}$ in $1 \%$ osmium tetroxide in $0.1 \mathrm{M}$ cacodylate buffer, dehydrated and embedded in Spurr resin ${ }^{70}$. For ultrastructural evaluation of the nerve terminal region of IHCs, ultrathin $(80-90 \mathrm{~nm})$ sections were cut in radial planes from the apical coil, mounted on 200 mesh thin bar copper grids (Agar Scientific, Stansted, UK) and stained in $2 \%$ uranyl acetate in $70 \%$ ethanol for $20 \mathrm{~min}$, followed by $0.4 \%$ lead citrate dissolved at high $\mathrm{pH}$ in distilled water for $5 \mathrm{~min}$. They were examined in a JEOL 1230 TEM operated at $100 \mathrm{kV}$ accelerating voltage. Digital images were acquired in using a Megaview III (SIS systems, Olympus Microscopes Ltd). The height and width of stereocilia were measured as previously described ${ }^{71}$. Semi-thin sections $(250-270 \mathrm{~nm})$ of the organ of Corti were obtained in a radial plane and examined unstained in a JEOL 1230 TEM operated at $100 \mathrm{kV}$. The height and width was measured using imageJ (NIH). The heights of first row IHC stereocilia (s1) were measured only when $90-100 \%$ of their length from the distal tip lay within the section (confirmed by examination of the adjacent serial section). The full length of second row (s2) stereocilia was readily captured in these sections and was measured to the maximum distal tip including the bevelled portion where present. The width was measured at half maximum height of each stereocilium. For TEM, $\geq 3$ mice were processed for each set of experiments and for each genotypes. Images were taken from the same region (around $12 \mathrm{kHz}$ ) used for the electrophysiological recordings.

Statistical analysis. Statistical comparisons of means were made by Student's twotailed $t$ test or for multiple comparisons, analysis of variance (one-way and twoway ANOVA followed by Bonferroni's test) were applied. $P<0.05$ was selected as the criterion for statistical significance. Mean values are quoted in text and figures as means \pm SEM. apart those referring to ABR and TEM measurements, which are reported as means $\pm \mathrm{SD}$. Only mean values with a similar variance between groups were compared. Electrophysiological recordings in which the IHC leak conductance, normally calculated between -84 and $-94 \mathrm{mV}$, was significantly larger than that previous reported for both immature and adult cells ${ }^{14}$ or with a residual series resistance $\left(R_{\mathrm{s}}\right)$ after compensation $>5 \mathrm{MOhm}$ were excluded from the analysis. Animals of either sex were randomly assigned to the different experimental groups. No statistical methods were used to define sample size, which was defined based on previous published similar work from our laboratory. The majority of the experiments were performed blindly to animal genotyping.

\section{Data availability}

The data supporting the findings of this study are available within the paper and its Supplementary Information files and from the corresponding author upon reasonable request.

Received: 3 August 2017 Accepted: 21 August 2018

Published online: 01 October 2018

\section{References}

1. Goodyear, R. J., Marcotti, W., Kros, C. J. \& Richardson, G. P. Development and properties of stereociliary link types in hair cells of the mouse cochlea. J. Comp. Neurol. 485, 75-85 (2005).

2. Kazmierczak, P. et al. Cadherin 23 and protocadherin 15 interact to form tip-link filaments in sensory hair cells. Nature 449, 87-91 (2007).

3. Barr-Gillespie, P. G. Assembly of hair bundles, an amazing problem for cell biology. Mol. Biol. Cell. 26, 2727-2732 (2015).

4. Corns, L. F., Johnson, S. L., Kros, C. J. \& Marcotti, W. Calcium entry into stereocilia drives adaptation of the mechanoelectrical transducer current of mammalian cochlear hair cells. Proc. Natl Acad. Sci. USA 111, 14918-14923 (2014).

5. Johnson, S. L., Kennedy, H. J., Holley, M. C., Fettiplace, R. \& Marcotti, W. The resting transducer current drives spontaneous activity in prehearing mammalian cochlear inner hair cells. J. Neurosci. 32, 10479-10483 (2012)

6. Bosher, S. K. \& Warren, R. L. Very low calcium content of cochlear endolymph, an extracellular fluid. Nature 273, 377-378 (1978).

7. Bosher, S. K. \& Warren, R. L. A study of the electrochemistry and osmotic relationships of the cochlear fluids in the neonatal rat at the time of the development of the endocochlear potential. J. Physiol. 212, 739-7761 (1971).

8. Johnson, S. L., Beurg, M., Marcotti, W. \& Fettiplace, R. Prestin-driven cochlear amplification is not limited by the outer hair cell membrane time constant. Neuron 70, 1143-1154 (2011).

9. Kros, C. J., Ruppersberg, J. P. \& Rüsch, A. Expression of a potassium current in inner hair cells during development of hearing in mice. Nature 394, 281-284 (1998).

10. Johnson, S. L. et al. Connexin-mediated signaling in nonsensory cells is crucial for the development of sensory inner hair cells in the mouse cochlea. J. Neurosci. 37, 258-268 (2017)

11. Zhang-Hooks, Y., Agarwal, A., Mishina, M. \& Bergles, D. E. NMDA receptors enhance spontaneous activity and promote neuronal survival in the developing cochlea. Neuron 89, 337-350 (2016).

12. Johnson, S. L. et al. Presynaptic maturation in auditory hair cells requires a critical period of sensory-independent spiking activity. Proc. Natl Acad. Sci. USA 110, 8720-8725 (2013).

13. Clause, A. et al. The precise temporal pattern of prehearing spontaneous activity is necessary for tonotopic map refinement. Neuron $\mathbf{8 2}, 822-835$ (2014).

14. Marcotti, W., Johnson, S. L., Holley, M. C. \& Kros, C. J. Developmental changes in the expression of potassium currents of embryonic, neonatal and mature mouse inner hair cells. J. Physiol. 548, 383-400 (2003).

15. Alagramam, K. N. et al. Mutations in protocadherin 15 and cadherin 23 affect tip links and mechanotransduction in mammalian sensory hair cells. PLoS ONE 6, e19183 (2011).

16. Marcotti, W., Géléoc, G. S. G., Lennan, G. W. T. \& Kros, C. J. Developmental expression of an inwardly rectifying potassium conductance in inner and outer hair cells along the mouse cochlea. Pflug. Arch. 439, 113-122 (1999).

17. Marcotti, W., Erven, A., Johnson, S. L., Steel, K. P. \& Kros, C. J. Tmc1 is necessary for normal functional maturation and survival of inner and outer hair cells in the mouse cochlea. J. Physiol. 574, 677-698 (2006).

18. Kawashima, Y. et al. Mechanotransduction in mouse inner ear hair cells requires transmembrane channel-like genes. J. Clin. Invest. 121, 4796-4809 (2011).

19. Roux, I. et al. Myosin VI is required for the proper maturation and function of inner hair cell ribbon synapses. Hum. Mol. Genet. 18, 4615-4628 (2009). 
20. Marcotti, W. et al. The acquisition of mechano-electrical transducer current adaptation in auditory hair cells requires myosin VI. J. Physiol. 594, 3667-3681 (2016).

21. Self, T. et al. Role of myosin VI in the differentiation of cochlear hair cells. Dev. Biol. 214, 331-341 (1999).

22. Self, T. et al. Shaker-1 mutations reveal roles for myosin VIIA in both development and function of cochlear hair cells. Development 125, 557-566 (1998).

23. Michalski, N. et al. Harmonin-b, an actin-binding scaffold protein, is involved in the adaptation of mechanoelectrical transduction by sensory hair cells. Pflug. Arch. 459, 115-130 (2009).

24. Caberlotto, E. et al. Usher type $1 \mathrm{G}$ protein sans is a critical component of the tip-link complex, a structure controlling actin polymerization in stereocilia. Proc. Natl Acad. Sci. USA 108, 5825-5830 (2011).

25. Pan, L., Yan, J., Wu, L. \& Zhang, M. Assembling stable hair cell tip link complex via multidentate interactions between harmonin and cadherin 23 . Proc. Natl Acad. Sci. USA 106, 5575-5580 (2009).

26. Gregory, F. D. et al. Harmonin inhibits presynaptic Cav1.3 $\mathrm{Ca}^{2+}$ channels in mouse inner hair cells. Nat. Neurosci. 14, 1109-1111 (2011).

27. Ricci, A. J. \& Fettiplace, R. Calcium permeation of the turtle hair cell mechanotransducer channel and its relation to the composition of endolymph. J. Physiol. 506, 159-173 (1998).

28. Tritsch, N. X., Yi, E., Gale, J. E., Glowatzki, E. \& Bergles, D. E. The origin of spontaneous activity in the developing auditory system. Nature 450, 50-55 (2007).

29. Johnson, K. R. et al. Mouse models of USH1C and DFNB18: phenotypic and molecular analyses of two new spontaneous mutations of the Ush1c gene. Hum. Mol. Genet. 12, 3075-3086 (2003).

30. Boëda, B. et al. Myosin VIIa, harmonin, and cadherin 23, three Usher I gene products, cooperate to shape the sensory hair cell bundle. EMBO J. 21, 6689-6699 (2002).

31. Kros, C. J. et al. Reduced climbing and increased slipping adaptation in cochlear hair cells of mice with Myo7a mutations. Nat. Neurosci. 5, 41-47 (2002).

32. Lord, E. M. \& Gates, W. H. Shaker, a new mutation of the house mouse (Musmusculus). Am. Nat. 63, 435-442 (1929).

33. Farris, H. E., LeBlanc, C. L., Goswami, J. \& Ricci, A. J. Probing the pore of the auditory hair cell mechanotransducer channel in turtle. J. Physiol. 558, 769-792 (2004).

34. Kirkwood, N. K. et al. d-Tubocurarine and berbamine: alkaloids that are permeant blockers of the hair cell's mechano-electrical transducer channel and protect from aminoglycoside toxicity. Front. Cell. Neurosci. 11, 262 (2017).

35. Marcotti, W., Johnson, S. L. \& Kros, C. J. A transiently expressed SK current sustains and modulates action potential activity in immature mouse inner hair cells. J. Physiol. 560, 691-708 (2004).

36. Katz, E. et al. Developmental regulation of nicotinic synapses on cochlear inner hair cells. J. Neurosci. 24, 7814-7820 (2004).

37. Maison, S. F., Adams, J. C. \& Liberman, M. C. Olivocochlear innervation in the mouse: immunocytochemical maps, crossed versus uncrossed contributions, and transmitter colocalization. J. Comp. Neurol. 455, 406-416 (2003).

38. Glowatzki, E. \& Fuchs, P. A. Cholinergic synaptic inhibition of inner hair cells in the neonatal mammalian cochlea. Science 288, 2366-2368 (2000).

39. Johnson, S. L. et al. Cholinergic efferent synaptic transmission regulates the maturation of auditory hair cell ribbon synapses. Open Biol. 3, 130163 (2013).

40. Gómez-Casati, M. E., Fuchs, P. A., Elgoyhen, A. B. \& Katz, E. Biophysical and pharmacological characterization of nicotinic cholinergic receptors in rat cochlear inner hair cells. J. Physiol. 566, 103-118 (2005).

41. Tritsch, N. X., Yi, E., Gale, J. E., Glowatzki, E. \& Bergles, D. E. The origin of spontaneous activity in the developing auditory system. Nature 450, 50-55 (2007).

42. Tritsch, N. X. et al. Calcium action potentials in hair cells pattern auditory neuron activity before hearing onset. Nat. Neurosci. 13, 1050-1052 (2010).

43. Sonntag, M., Englitz, B., Kopp-Scheinpflug, C. \& Rübsamen, R. Early postnatal development of spontaneous and acoustically evoked discharge activity of principal cells of the medial nucleus of the trapezoid body: an in vivo study in mice. J. Neurosci. 29, 9510-9520 (2009).

44. Kandler, K., Clause, A. \& Noh, J. Tonotopic reorganization of developing auditory brainstem circuits. Nat. Neurosci. 12, 711-717 (2009).

45. Snyder, R. L. \& Leake, P. A. Topography of spiral ganglion projections to cochlear nucleus during postnatal development in cats. J. Comp. Neurol. 384, 293-311 (1997).

46. Mostafapour, S. P., Cochran, S. L., Del Puerto, N. M. \& Rubel, E. W. Patterns of cell death in mouse anteroventral cochlear nucleus neurons after unilateral cochlea removal. J. Comp. Neurol. 426, 561-571 (2000)
47. Tierney, T. S., Russell, F. A. \& Moore, D. R. Susceptibility of developing cochlear nucleus neurons to deafferentation-induced death abruptly ends just before the onset of hearing. J. Comp. Neurol. 378, 295-306 (1997).

48. Berridge, M. J., Lipp, P. \& Bootman, M. D. The versatility and universality of calcium signalling. Nat. Rev. Mol. Cell Biol. 1, 11-21 (2000).

49. Toth, A. B., Shum, A. K. \& Prakriya, M. Regulation of neurogenesis by calcium signaling. Cell Calcium 59, 124-134 (2016).

50. Vélez-Ortega, A. C., Freeman, M. J., Indzhykulian, A. A., Grossheim, J. M. \& Frolenkov, G. I. Mechanotransduction current is essential for stability of the transducing stereocilia in mammalian auditory hair cells. eLife 6, e24661 (2017).

51. Beurg, M., Nam, J.-H., Chen, Q. \& Fettiplace, R. Calcium balance and mechanotransduction in rat cochlear hair cells. J. Neurophysiol. 104, 18-34 (2010).

52. Kujawa, S. G. \& Liberman, M. C. Synaptopathy in the noise-exposed and aging cochlea: primary neural degeneration in acquired sensorineural hearing loss. Hear. Res. 330, 191-199 (2015).

53. Zachary, S. P. \& Fuchs, P. A. Re-emergent inhibition of cochlear inner hair cells in a mouse model of hearing loss. J. Neurosci. 35, 9701-9706 (2015).

54. Katz., E. \& Elgoyhen, A. B. Short-term plasticity and modulation of synaptic transmission at mammalian inhibitory cholinergic olivocochlear synapses. Front. Syst. Neurosci. 8, 224 (2014).

55. Simmons, D. D. Development of the inner ear efferent system across vertebrate species. J. Neurobiol. 53, 228-250 (2002).

56. Shnerson, A., Devigne, C. \& Pujol, R. Age-related changes in the C57BL/6J mouse cochlea. II. Ultrastructural findings. Dev. Brain. Res. 2, 77-88 (1982).

57. Ruel, J. et al. Physiology, pharmacology and plasticity at the inner hair cell synaptic complex. Hear. Res. 227, 19-27 (2007).

58. Lauer, A. M., Fuchs, P. A., Ryugo, D. K. \& Francis, H. W. Efferent synapses return to inner hair cells in the aging cochlea. Neurobiol. Aging 33, 2892-2902 (2012).

59. Pickles, J. O., Osborne, M. P. \& Comis, S. D. Vulnerability of tip links between stereocilia to acoustic trauma in the guinea pig. Hear. Res. 25, 173-83 (1987).

60. Liberman, M. C. Chronic ultrastructural changes in acoustic trauma: serialsection reconstruction of stereocilia and cuticular plates. Hear. Res. 26, 65-88 (1987).

61. Bohne, B. A., Gruner, M. M. \& Harding, G. W. Morphological correlates of aging in the chinchilla cochlea. Hear. Res. 48, 79-91 (1990).

62. Geng, R. et al. The mechanosensory structure of the hair cell requires clarin-1, a protein encoded by Usher syndrome III causative gene. J. Neurosci. 32, 9485-9498 (2012).

63. Ingham, N. J., Pearson, S. \& Steel, K. P. Using the auditory brainstem response (ABR) to determine sensitivity of hearing in mutant mice. Curr. Protoc. Mouse Biol. 1, 279-287 (2011).

64. Müller, M., von Hünerbein, K., Hoidis, S. \& Smolders, J. W. A physiological place-frequency map of the cochlea in the CBA/J mouse. Hear. Res. 202, 63-73 (2005).

65. Müller, M. The cochlear place-frequency map of the adult and developing Mongolian gerbil. Hear. Res. 94, 148-156 (1996).

66. Ceriani, F. et al. Spontaneous and coordinated $\mathrm{Ca}^{2+}$ activity of cochlear sensory and non-sensory cells drives the maturation of $\mathrm{OHC}$ afferent innervation. Preprint at: https://doi.org/10.1101/317172 (2018).

67. Salt, A. N., Inamura, N., Thalmann, R. \& Vora, A. Calcium gradients in inner ear endolymph. Am. J. Otolaryngol. 10, 371-375 (1989).

68. el-Amraoui, A. et al. Human Usher $1 \mathrm{~B} /$ mouse shaker-1: the retinal phenotype discrepancy explained by the presence/absence of myosin VIIA in the photoreceptor cells. Hum. Mol. Genet. 5, 1171-1178 (1996).

69. Davies, S. J. \& Forge, A. Preparation of the mammalian organ of Corti for scanning electron microscopy. J. Microsc. 147, 89-101 (1987).

70. Furness, D. N. \& Hackney, C. M. Cross-links between stereocilia in the guinea pig cochlea. Hear. Res. 18, 177-188 (1985).

71. Furness, D. N., Mahendrasingam, S., Ohashi, M., Fettiplace, R. \& Hackney, C. $\mathrm{M}$. The dimensions and composition of stereociliary rootlets in mammalian cochlear hair cells: comparison between high- and low-frequency cells and evidence for a connection to the lateral membrane. J. Neurosci. 28, 6342-6353 (2008).

\section{Acknowledgements}

We thank J. Pass and L. Preite for generating the Ush1c and Myo7a tmlc allele conditional knockout mice, the Sanger Institute Mouse Genetics Project and EUCOMM for providing the Myo7a and Ush1c tmla alleles; Neil Ingham for advice on ABR measurements; Maria Pakendorf for helping with the genotyping and Michelle Bird for 
her assistance with the transgenic mouse colonies. This work was supported by the Wellcome Trust to W.M. (102892) and K.P.S. (100669), the MRC (G0100798 and MR/ K005561/1) to C.J.K. and a BBSRC Research Studentship to T.R. S.L.J. is a Royal Society University Research Fellow.

\section{Author contributions}

L.F.C., S.L.J., T.R., K.M.R., A.H., F.C., S.S., K.P.S., A.F., C.P., D.N.F., C.J.K., W.M. contributed to the collection and analysis of the data. W.M. conceived and coordinated the study. L.F.C., C.J.K. and W.M. wrote the paper.

\section{Additional information}

Supplementary Information accompanies this paper at https://doi.org/10.1038/s41467018-06307-w.

Competing interests: The authors declare no competing interests.

Reprints and permission information is available online at http://npg.nature.com/ reprintsandpermissions/
Publisher's note: Springer Nature remains neutral with regard to jurisdictional claims in published maps and institutional affiliations.

\section{(c) (i)}

Open Access This article is licensed under a Creative Commons Attribution 4.0 International License, which permits use, sharing, adaptation, distribution and reproduction in any medium or format, as long as you give appropriate credit to the original author(s) and the source, provide a link to the Creative Commons license, and indicate if changes were made. The images or other third party material in this article are included in the article's Creative Commons license, unless indicated otherwise in a credit line to the material. If material is not included in the article's Creative Commons license and your intended use is not permitted by statutory regulation or exceeds the permitted use, you will need to obtain permission directly from the copyright holder. To view a copy of this license, visit http://creativecommons.org/ licenses/by/4.0/.

(C) The Author(s) 2018 